The paper as a non-peer reviewed EarthArXiv preprint

\title{
A NEW APPROACH TO IDENTIFY ON-GROUND LAMP TYPES FROM NIGHT-TIME ISS IMAGES
}

\author{
Natalia Rybnikova ${ }^{a, b, c, *}$, Alejandro Sánchez de Miguel ${ }^{\text {dee }}$, Sviatoslav Rybnikov ${ }^{f, g}$, Anna Brook ${ }^{c}$ \\ a Dept. of Mathematics, University of Leicester, Leicester LE1 7RH, United Kingdom \\ ${ }^{\mathrm{b}}$ Dept. of Natural Resources and Environmental Management, University of Haifa, Haifa 3498838, Israel \\ ${ }^{\mathrm{c}}$ Dept. of Geography and Environmental Studies, University of Haifa, Haifa 3498838, Israel \\ ${ }^{\mathrm{d}}$ Environment and Sustainability Institute, University of Exeter, Penryn Campus, Penryn, Cornwall, TR10 9FE, \\ United Kingdom
}

${ }^{\text {e }}$ Dept. Física de la Tierra y Astrofísica, Instituto de Física de Partículas y del COSMOS (IPARCOS), Universidad Complutense de Madrid, 28040, Madrid, Spain

${ }_{\mathrm{f}}^{\mathrm{f}}$ Institute of Evolution, University of Haifa, Haifa 3498838, Israel

${ }^{\mathrm{g}}$ Dept. of Evolutionary and Environmental Biology, University of Haifa, Haifa 3498838, Israel

*Corresponding author. Email: nrybhiko@campus.haifa.ac.il, nataliya.rybnikova@gmail.com

\begin{abstract}
Artificial night-time light (NTL), emitted by various on-ground human activities, becomes further intensive in many regions worldwide. Its adverse effects on humans' and ecosystems' health crucially depend on the light spectrum, making the remote discrimination between different lamps a highly important task. However, such studies remain extremely limited, and none of them exploits freely available satellite imagery. In the analysis, the possibility to remotely assess the relative contribution of different lamp types into outdoor lighting is tested. For this sake, the radiometrically calibrated ISS RGB image is used. Spatial resolution of the image is $\sim 20$ meters, implying that each pixel may represent a mixture of different lamp types. Unmixing analysis to the detailed spectral signatures of the corresponding in situ measurements is performed, with 'pure' lamps' signatures as the endmembers. Afterwards, statistical models to reproduce the
\end{abstract}


The paper as a non-peer reviewed EarthArXiv preprint

results of unmixing based on the broad-band RGB image from the ISS are run. The built models predict well (with $R^{2}$ reaching $~ 0.87$ ) the contribution of high-pressure sodium (HPS) and metalhalide (MH) lamps, the most spread in the study area (Haifa, Israel). The restored map for HPS allocation demonstrates high concordance with the network of municipal roads, while that for $\mathrm{MH}$ shows notable coincidence with the industrial facilities and the airport.

Keywords: RGB night-time imagery, ISS, radiometric calibration, in situ measurement, lamp type, unmixing.

\section{Introduction}

Artificial night-time light (NTL), emitted by various on-ground human activities, becomes further intensive in many countries, making the world brighter (Cinzano et al., 2001; Falchi et al., 2016; Kyba et al., 2017; Zheng et al., 2021). At the same time, a huge amount of empirical evidence has been accumulated for adverse effects of NTL on both humans (Garcia-Saenz et al., 2018; Haim and Portnov, 2013; Kloog et al., 2009; McFadden et al., 2014) and ecosystems (Gaston et al., 2013; Hölker et al., 2010; Longcore et al., 2004; Owens et al., 2020). An especially serious concern comes from the long-term cumulative effects of NTL, which remains almost unexplored (Lyytimäki, 2015). Besides, NTL also embarrasses professional astronomical observations (Kyba, 2018; Riegel, 1973; Zhang et al., 2017). With respect to the above-mentioned challenges, the necessity to regulate light pollution becomes further more recognized (Cho et al., 2011; Falchi and Bará, 2020; Morgan-Taylor, 2015).

The adverse effects of NTL are known to depend crucially on the light spectrum (Brainard et al., 2001; Gaston et al., 2014; Papamichael et al., 2012; Schroer et al., 2016). For instance, the shortwavelength light stronger suppresses melatonin production and distort circadian rhythms in mammals (Haim and Portnov, 2013; Hatori et al., 2017; Lockley et al., 2003), while the long- 
wavelength light stronger disrupts the magnetic orientation of migratory birds (Wiltschko et al., 1993). As far as adverse effects of NTL become more recognized to depend on light spectrum, multispectral satellite imagery analysis becomes more numerous (Guk and Levin, 2020; Huang et al., 2021; Levin and Duke, 2012; Rybnikova and Portnov, 2017; Zheng et al., 2018). Such studies usually aim at revealing associations between light of certain spectra and land-use types or economic activities. The assumption (either explicit or implicit) behind these studies is that different land use types or economic activities use predominantly certain lighting source type. In the meantime, direct discriminating between different lamp types based on satellite imagery would allow a more fine-tuned analysis of adverse health effects associated with NTL. In turn, this would contribute to elaborating more precise policies for diminishing light pollution.

Such studies, aiming to directly link NTL spectra with onground lamp types, remain, however, extremely limited (Elvidge et al., 2010; Hale et al., 2013; Sánchez de Miguel et al., 2019; Zheng et al., 2018). In two of them (Elvidge et al., 2010; Sánchez de Miguel et al., 2019), the authors tested the principal possibility to identify lamp type, proceeding from corresponding spectral signature, either detailed or aggregated. In the first study, Elvidge with co-authors analysed spectral signatures of 43 different lamps representing nine the most widespread lamp types, using ASD spectroradiometer, implying measuring the signatures from 400 to $2500 \mathrm{~nm}$ with $10 \mathrm{~nm}$ band width (Elvidge et al., 2010). They showed that discriminant analysis correctly classified all lamp types when based on their detailed spectra. The authors also succeeded to find a minimum set of broad bands ensuring sufficient classification quality: Under blue, green, red, and NIR bands (a slightly modified set represented on the Landsat Thematic Mapper), only $4.7 \%$ of the lamp types were classified incorrectly. In the second study by de Miguel with co-authors, it was demonstrated that main lamp types can often be separated using color-color diagrams with $G / R$ and $B / G$ ratios 
as the two coordinates (Sánchez de Miguel et al., 2019). At that, the RGB bands corresponded to Nikon D3s camera sensors, used by astronauts in the ISS. However, in both mentioned studies, the proposed lamp-type discriminating methods, although being based on spectral bands of existing satellites, were not tested on real imagery (Elvidge et al., 2010; Sánchez de Miguel et al., 2019).

To the best of our knowledge, the only explicit tests of such kind were performed in (Hale et al., 2013; Zheng et al., 2018). Thus, Hale with co-authors analysed a one-meter aerial image of the Birmingham city, UK, and a layer reporting location and type of lamp (Hale et al., 2013). They succeeded to classify four main lamp types with high accuracy (7.5\% error), based on three focal statistics: B and G/R ratio for pixels up to $1 \mathrm{~m}$ from the lamp centre and the maximum averaged RGB level for pixels between 2 and $4 \mathrm{~m}$ from the lamp centre. At that, RGB bands corresponded to those of Nikon D2X digital camera. Zheng with co-authors, in the meantime, used RGB highresolution $(0.92 \mathrm{~m})$ commercial satellite JL1-3B image to discriminate between HPS and LED lamps - two most widespread lighting sources in the study area, represented by Hangzhou, China (Zheng et al., 2018). The authors used RGB levels of brightly lit pixels of the image as input data for ISODATA clustering procedure; While unlabelled classes, generated by clustering algorithm, together with morphological characteristics of bright pixels, were used as inputs in decision tree classification procedure to discriminate HPS from LED lamps. The authors matched each group of bright pixels in the satellite image with lighting source type, obtained from the field survey and report that upon 446 available observations, overall accuracy of classification reaches $83.86 \%$. These studies, however, benefit from high-resolution aerial images available only for limited sites and are typically costly.

In the present study, we test for the possibility to identify on-ground lamp types from freely available satellite imagery of relatively coarse spatial and spectral resolution. For the study area of 
Haifa, Israel, we superimpose two NTL data sources: $(i)$ the radiometrically calibrated broadband RGB image provided by the ISS, and (ii) a set of in situ measurements with detailed spectral signatures conducted by ourselves. Since the ISS image is of $\sim 20$-meter resolution, each pixel likely represents a mixture of lamps. Thus, the detailed spectral signatures of the in situ measurements are first subjected to unmixing analysis, with the standard lamp types used as endmembers, - to estimate the relative contribution of different lamp types in each measurement. Afterward, we use the levels of RGB bands of the corresponding pixels in the ISS image and develop statistical models to predict the relative contribution of different lamp type (output) from the aggregated RGB data (input). Finally, we apply the successful models to all pixels from the ISS image to restore the maps of relative contribution of certain lamp types into outdoor lighting in Haifa area.

\section{Data Sources}

The ISS-produced NTL image of Haifa (ISS045-E-148262) was taken on November 29, 2015 with the Nikon D4 DSLR camera ("Search Photos," n.d.). The image was georeferenced and radiometrically calibrated by SAVESTARS Consulting SL ("Home - Savestars Consulting S.L.," n.d.) according to the procedure reported in (Sánchez de Miguel, 2021). In situ NTL measurements were performed in March 2015 with the Konica Minolta CL-500A spectrometer. Each of the 610 measurements reports spectral irradiance $\left(\mathrm{w} / \mathrm{m}^{2}\right)$ at 1-nm pitch from 360 to $780 \mathrm{~nm}$ (“Illuminance Spectrophotometer CL-500A," n.d.). Fig. 1 reports the original and the radiometrically calibrated RGB images from the ISS, overlaid with the in situ measurements localities. 


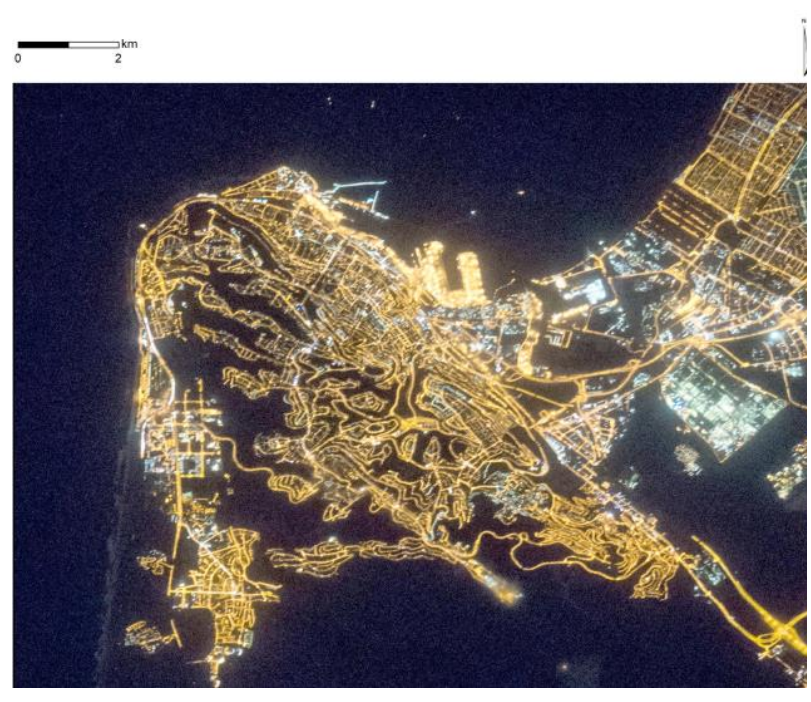

(a)

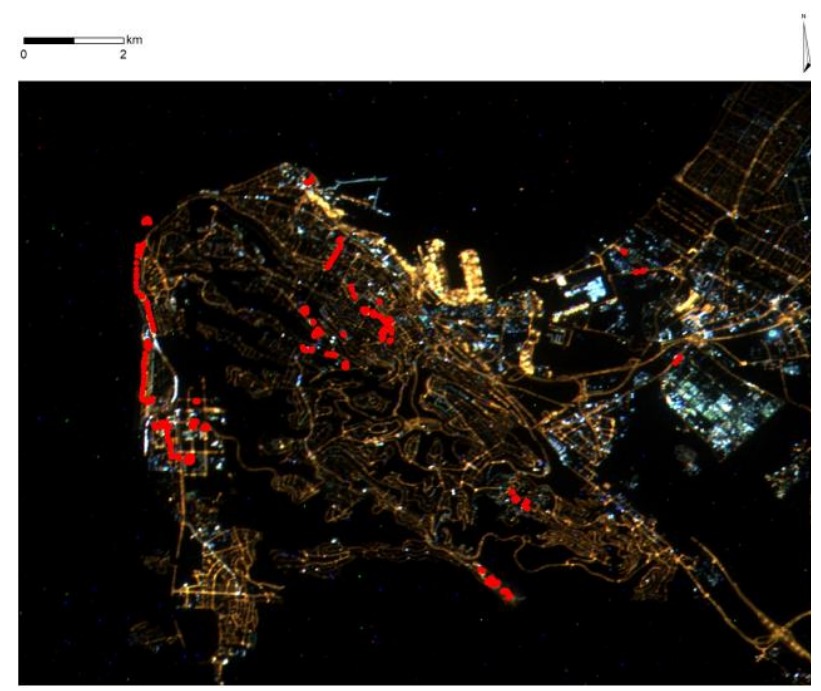

(b)

Figure 1: Georeferenced ISS-produced (taken on 29.11.2015 by Nikon D4 DSLR camera; ID ISS045-E-148262) (a) and radiometrically calibrated $(b)$ night-time image of the Haifa region. In situ measurements $(\mathrm{n}=610)$, performed in March 2015 via Konica Minolta CL-500A spectrometer, are marked by red dots in the left sub-figure.

The spectral signatures of standard lamp types were taken from the LICA UCM library (Tapia Ayuga et al., 2017). We examined spectral signatures of 81 lamps representing seven (out of nine reported by Elvidge et al. (2010)) the most popular lamp types: fluorescent (FL), metal-halide (MH), high-pressure sodium (HPS), low-pressure sodium (LPS), incandescent and halogen (I\&H), mercury-vapor (MV), and light-emitting diodes (LED). Two other widespread lighting types, liquid-fuel and pressurized-fuel lamps, were omitted due to the data unavailability.

\section{Methods}

The methodological scheme of the study is reported in Fig. 2 and described in detail in subsections below. 


\begin{tabular}{|c|c|c|c|}
\hline $\begin{array}{l}\text { Inputs: } \\
(*) \text { In situ measurements } \\
\text { of detailed spectra } \\
(* *) \text { ISS image pixels } \\
\text { of RGB spectra }\end{array}$ & $\begin{array}{l}\text { Inputs: } \\
\left({ }^{*}\right) \text { Lamps signatures } \\
\text { of detailed spectra } \\
\text { (LICA-UCM library) } \\
\left(*^{* *}\right) \text { (a) from outputs }\end{array}$ & $\begin{array}{l}\text { Inputs: } \\
\left({ }^{*}\right)(\text { b) from outputs } \\
\left({ }^{* *}\right)(c) \text { from outputs }\end{array}$ & $\begin{array}{l}\text { Inputs: } \\
(*) \text { ISS image of the } \\
\text { study area } \\
(* *)(d) \text { from outputs }\end{array}$ \\
\hline $\begin{array}{l}\text { (I) SELECTION OF } \\
\text { REPRESENTATIVE } \\
\text { GROUND TRUTH } \\
\text { OBSERVATIONS }\end{array}$ & $\begin{array}{l}\text { (II) UNMIXING } \\
\text { OVER } \\
\text { OBSERVATIONS } \\
\text { WITH DETAILED } \\
\text { SPECTRA }\end{array}$ & $\begin{array}{l}\text { (III) MODELLING } \\
\text { OVER } \\
\text { OBSERVATIONS } \\
\text { WITH RGB } \\
\text { SPECTRA }\end{array}$ & $\begin{array}{l}\text { (IV) RESTORING } \\
\text { LAMPS } \\
\text { CONTRIBUTION } \\
\text { INTO LIGHT } \\
\text { EMISSIONS FROM } \\
\text { THE STUDY AREA }\end{array}$ \\
\hline $\begin{array}{l}\text { Outputs: } \\
\text { (a) Ground truth of } \\
\text { detailed spectra } \\
\text { (b) Ground truth of } \\
\text { RGB spectra }\end{array}$ & $\begin{array}{l}\text { Outputs: } \\
\text { (c) Lamp type } \\
\text { contribution to } \\
\text { each ground truth } \\
\text { observation }\end{array}$ & $\begin{array}{l}\text { Outputs: } \\
\text { (d) Random Forest, } \\
\text { Neural Network, } \\
\text { Linear Regression } \\
\text { models }\end{array}$ & $\begin{array}{l}\text { Outputs: } \\
\text { (e) Maps of lamp } \\
\text { types contribution } \\
\text { into light emissions } \\
\text { for the study area }\end{array}$ \\
\hline
\end{tabular}

Figure 2: Methodological scheme of the study

\subsection{Selection of the representative in situ measurements for the ground truth}

Proceeding from the available data on relatively coarse spatial resolution of ISS image, with each pixel reporting emissions from multiple light sources, and simultaneously given the sporadic pointwise available in situ NTL measurements, we selected among 610 observations only those which in some sense coincided with corresponding pixels in the ISS image. Since each pixel might be characterized by RGB radiances only, we first simulated the radiances of synthetic RGB bands of in situ measurements as if they would appear on the ISS sensors of Nikon D4 DSLR camera, and then chose the observations with similar (to the corresponding ISS imagery pixel) RGB characteristics.

To simulate the radiance $R$ (of either red, green, or blue band), we used the augmented equation reported by Sanchez de Miguel et al. (2019):

$R=\frac{\int_{0}^{\infty} \phi(\lambda) T(\lambda) A(\lambda) d \lambda}{\int_{0}^{\infty} \phi_{A B}(\lambda) T(\lambda) A(\lambda) d \lambda}$ 
The paper as a non-peer reviewed EarthArXiv preprint

where

$\phi(\lambda)=$ spectrum of the lamp under analysis;

$T(\lambda)=$ spectral sensitivity of the synthetic band (in the present analysis, we used spectral responses of Nikon D4 Electronic Still Camera - the one produced the image under analysis, - reported in (Sánchez de Miguel et al., 2019)) - see Fig. 3(a);

$A(\lambda)=$ atmospheric transmittance (in the present analysis, we applied the MODTRAN $®$ computer code ("MODTRAN $®$," n.d.) for the simulation of atmospheric transmittance of light emissions through the atmosphere over the study area at the time when in situ measurements were performed) - see Fig. 3(b);

$\phi_{A B}(\lambda)=$ reference spectrum of $\mathrm{AB}$ magnitude system, defined for a source of constant spectral density flux of 3631 Janskys across the spectral range of the band (Sánchez de Miguel et al., 2019) - see Fig. 3(c).

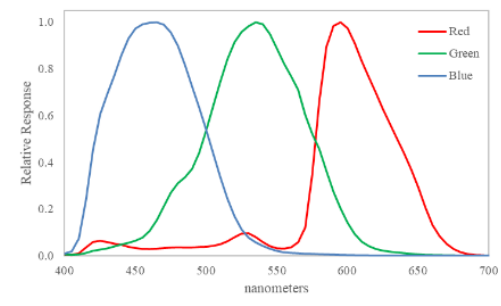

(a)

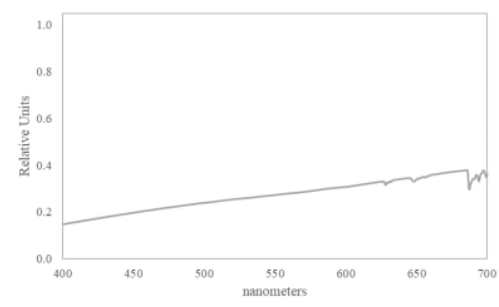

(b)

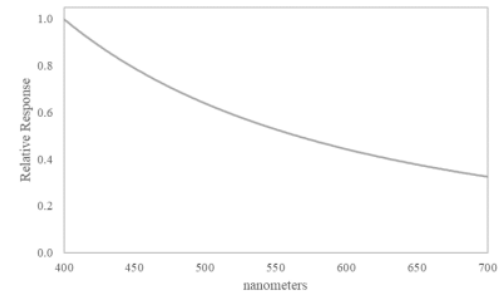

(c)

Figure 3: Graphical illustration of the constituents for synthetic bands' radiance computation: Spectral sensitivity of RGB bands of Nikon D4 DSLR camera (a), Atmospheric transmittance $(b)$, and Reference spectrum of $\mathrm{AB}$ magnitude system (c).

As a measure of similarity between RGB radiances, reported by pixels of calibrated ISS image, and corresponding in situ measurements, we used Euclidian distance in the coordinate system, represented by $\mathrm{B} / \mathrm{G}$ and $\mathrm{G} / \mathrm{R}$ ratios. Given the variance of such a distance $\left(d_{\max }=2.00\right)$, we settled the threshold of $d<0.2$. 


\subsection{Unmixing of the detailed spectral signatures of the representative in situ measurements}

The detailed spectral signatures of the representative in situ measurements (see subsection 3.1) were subjected to unmixing analysis. As the endmembers (i.e., spectra of pure 'materials' - see (Shi and Wang, 2014)), we used the detailed spectral signatures of the standard lamps from LICAUCM library. The endmembers' signatures are shown in Fig. 4. For unmixing analysis, we used the FNNLS algorithm (Bro and De Jong, 1997), implemented in MATLAB v.R2020b. The algorithm returned the percentages of all endmember lamps in each of the pre-selected in situ measurements. The obtained percentages were then aggregated within lamp types, and the sums were normalized to unit.

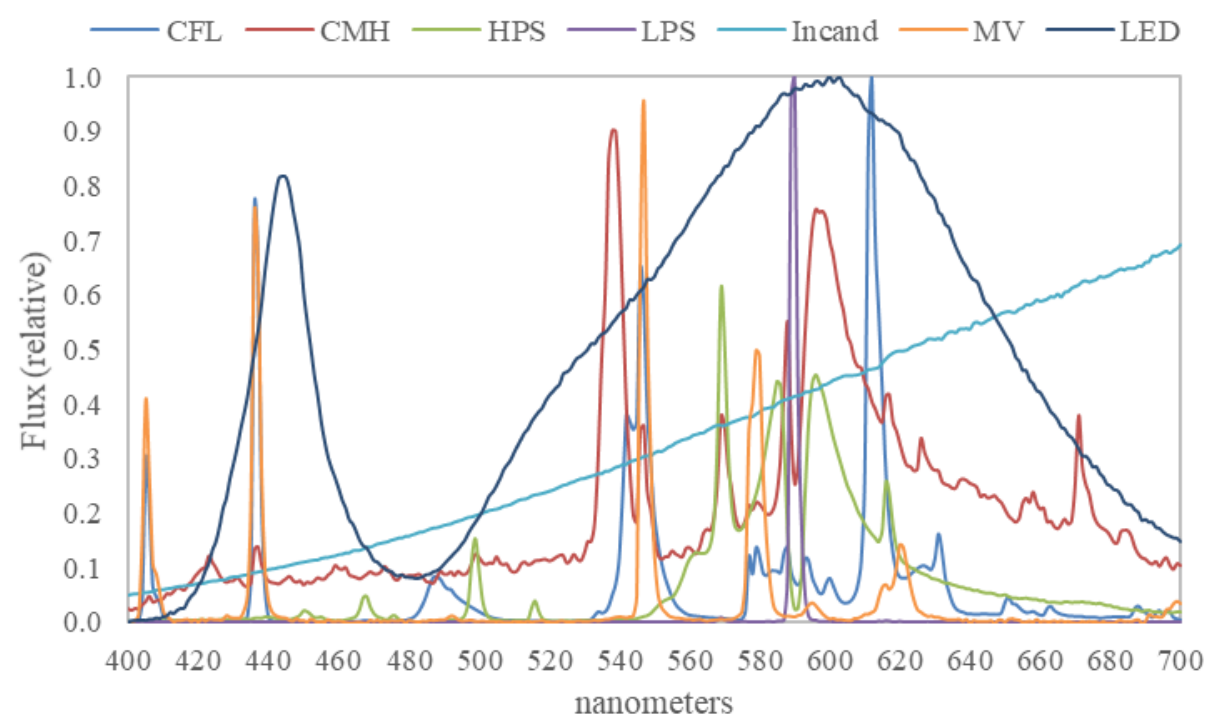

Figure 4: Spectral signatures of representatives of each lamp type used in the analysis.

Note: The following lamps' signatures are depicted: 'CFL' = Compact Fluorescent Lamp of 2776K; 'CMH' = Ceramic Metal Halide of 2829K; 'HPS' = High Pressure Sodium of 2005K; 'LPS' = Low Pressure Sodium of 1701K; 'Incand' $=$ Incandescent Tungsten of 2805K; 'MV' = Mercury Vapor of 4717K; 'LED' = LED of 3033K. 


\subsection{Statistical Models to predict the relative contribution of different lamp types from the ISS} image

The percentage of each lamp type, obtained in the unmixing analysis (Subsection 3.2), served as the dependent variable in a set of statistical models. As the explanatory variables, we tried different characteristics of the pixels of the calibrated ISS image: ( $i$ ) radiance in the red, green and blue bands per se; (ii) their ratios $(\mathrm{G} / \mathrm{R}$ and $\mathrm{B} / \mathrm{G}$, or $\mathrm{GG} / \mathrm{RB}$ ratio), and an additional derivative characteristic describing the pixel's 'proximity' to the lamp type in question. This distance was included in the models since we found that different lamps within each of the lamp type tend to lie along straight lines in the $\mathrm{G} / \mathrm{R}, \mathrm{B} / \mathrm{G}$ coordinate plane (see Fig. 5). We tried several formalizations of such a distance: $(i)$ the ratio between $\mathrm{B} / \mathrm{G}$ and $\mathrm{G} / \mathrm{R}$ of the pixel, as a measure of the line's slope; (ii) Euclidean distance from the pixel to the line representing the lamp type in question, and (iii) Mahalanobis distance from the pixel to the cloud representing the lamp type in question, which accounts for both the centre of mass and the direction of the cloud (Mahalanobis, 1936).

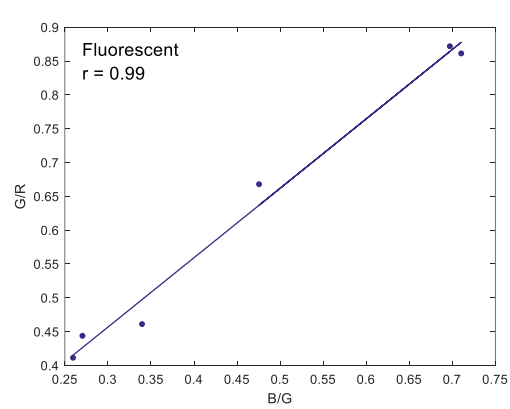

(a)

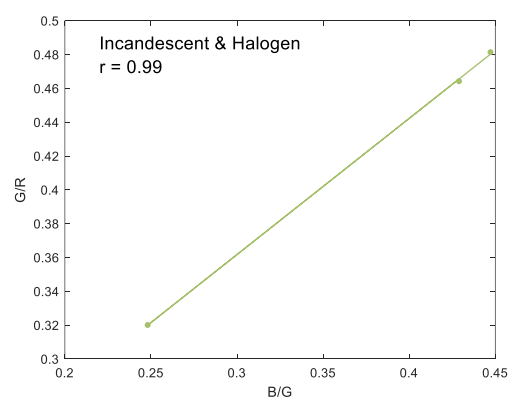

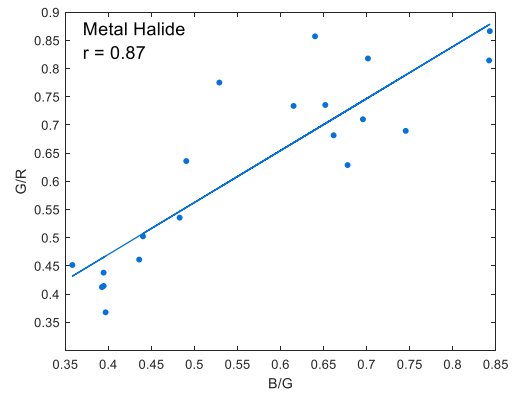

(b)

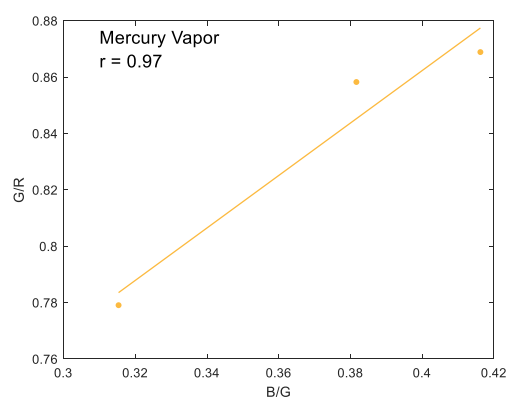

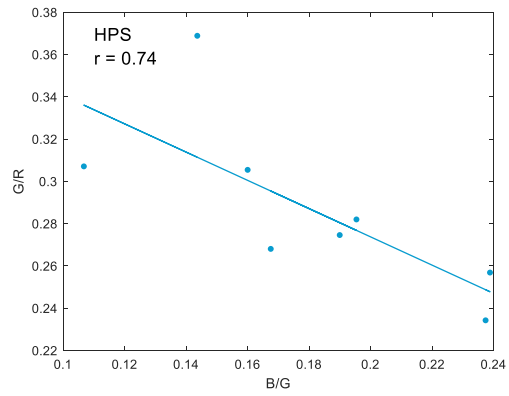

(c)

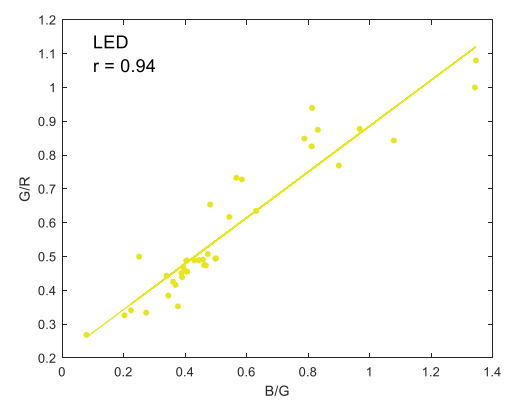


The paper as a non-peer reviewed EarthArXiv preprint

(d)

(e)

$(f)$

Figure 5: Simulated synthetic bands of the lamps: B/G vs. G/R ratios.

Note: LPS lamp, reporting $\mathrm{G} / \mathrm{R}=0.18$ and $\mathrm{B} / \mathrm{G}=0.02$, is the only representative of the type, and is not depicted in the figure

We examined statistical models of several classes: linear regression, neural network, and random forest. All models were run in ORANGE v.3.28 with the default settings. Specifically, linear regression was applied with intercept and without regularization. As a neural network, we used a multi-layer perceptron with backpropagation; the model parameters were the following: number of neurons in hidden layer is 100 , number of hidden layers is 1 , activation function is ReLu, solver for weight optimization is stochastic gradient-based optimizer, L2 penalty parameter is 0.0001 , maximal number of iterations is 200 . In random forest models, the number of trees was settled to 10, arbitrary set of attributes and limit depth of individual trees were left unchecked, and subsets smaller than 5 were required not to be split. The whole set of observations was split into the training (90\%) and the testing (10\%) subsets; the models were run ten times, and the average values were assigned to each model as its performance score. The input database used in the analysis is available from the authors upon request.

\subsection{Restoring the relative contributions of different lamp types into light emissions in Haifa}

Finally, the best-performing models (Subsection 3.3) were applied to the radiometrically calibrated ISS image (see Subsection 3.1), and estimates for different lamps' contribution into light emissions from the study area were obtained and depicted.

\section{Results}

Among all initially available in situ measurements, we chose the set of representative measurements - those deviating from the corresponding pixels of the radiometrically calibrated ISS image by less than 0.2 in terms of the Euclidian distance in the $G / R, B / G$ coordinate plane (see 
Subsection 3.1). Overall, we obtained 196 measurements; their main characteristics are reported in Fig. 6.

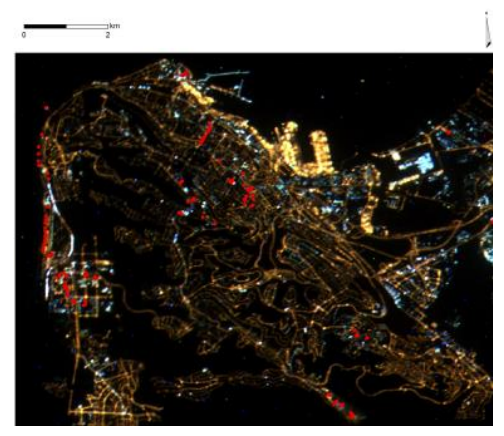

(a)

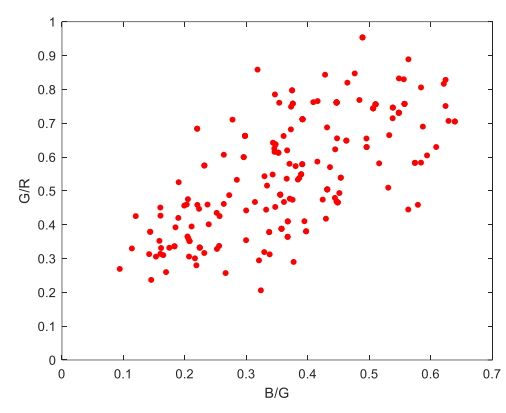

(b)

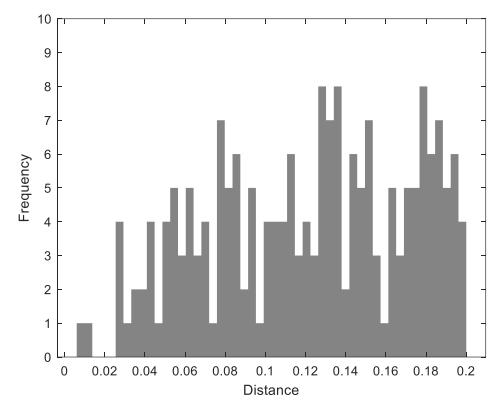

(c)

Figure 6: Main characteristics of selected representative ground truth measurements: Localities (marked as red dots) $(a), \mathrm{G} / \mathrm{R} \& \mathrm{~B} / \mathrm{G}$ ratios $(b)$, and Euclidian distances distribution from the corresponding ISS pixel in $\mathrm{G} / \mathrm{R}, \mathrm{B} / \mathrm{G}$ coordinate system $(c)$

The detailed spectral signatures of the obtained 196 representative in situ measurements were then subjected to unmixing analysis (see subsection 3.2). The results of the unmixing, i.e. the percentages of the seven endmember lamp types, are reported in the Supplementary Table S1. In the table we also report, for each in situ measurement, the highest correlation between its detailed spectral signature and the signatures of the lamps from the LICA-UCM library. As one can see from the table, the measurements with predominant percentage of a certain lamp type (marked grey) simultaneously demonstrated high correlation with this lamp type. Overall, HPS lamps were the most widespread in Haifa in 2015 (average percentage 32.8\%), followed by MH lamps (22.0\%), while LED lamps were considerably less frequent (15.6\%).

Table 1 reports the performance of three alternative statistical models (linear regression, neural network, and random forest) developed to explain the variance of each lamp type percentage, under various sets of predictors, for the training and the testing sets (see Subsection 3.3). As can it be seen from the table, the performance is higher for the models with $\mathrm{G} / \mathrm{R}$ and $\mathrm{B} / \mathrm{G}$ ratios as predictors, compared to those with R, G and B bands per se. For all dependent variables and all predictor sets, 
random forest models perform better than either linear regression or neural network models. For three lamp types (HPS, MH, and MV), random forest models containing $\mathrm{G} / \mathrm{R}$ and $\mathrm{B} / \mathrm{G}$ ratios as predictors demonstrate high performance both for the training and the testing sets: $R^{2}>0.782$ (Table 1 , predictor sets $\left.2^{\text {nd- }} 4^{\text {th }}\right)$.

Table 1: The performance of models (in terms of $R^{2}$ ) with alternative predictor sets, for the training and the testing sets (Dependent variable $=$ Percentage of a certain lamp type)

\begin{tabular}{|c|c|c|c|c|c|c|c|c|}
\hline \multirow{2}{*}{$\begin{array}{l}\text { Model } \\
\text { Type }\end{array}$} & \multirow{2}{*}{ Subset } & \multicolumn{7}{|c|}{ Lamp Type } \\
\hline & & HPS & $\mathrm{MH}$ & LED & CFL & LPS & Incand & MV \\
\hline \multicolumn{9}{|c|}{ Predictor set $1: R, G, B$} \\
\hline \multirow{2}{*}{$\begin{array}{l}\text { Linear } \\
\text { regression }\end{array}$} & Training & 0.330 & 0.238 & 0.021 & 0.056 & 0.161 & 0.079 & 0.172 \\
\hline & Testing & 0.454 & 0.140 & 0.004 & 0.041 & 0.125 & 0.149 & 0.158 \\
\hline \multirow{2}{*}{$\begin{array}{l}\text { Neural } \\
\text { network }\end{array}$} & Training & 0.387 & 0.043 & -0.435 & -0.296 & -0.920 & -0.298 & -0.679 \\
\hline & Testing & 0.354 & 0.341 & -0.363 & -0.449 & -1.193 & -0.664 & -0.177 \\
\hline \multirow{2}{*}{$\begin{array}{l}\text { Random } \\
\text { forest }\end{array}$} & Training & 0.887 & 0.842 & 0.751 & 0.773 & 0.839 & 0.835 & 0.832 \\
\hline & Testing & 0.442 & 0.819 & 0.510 & 0.523 & 0.340 & 0.089 & 0.701 \\
\hline \multicolumn{9}{|c|}{ Predictor set 2: $G / R, B / G, G G / R B$} \\
\hline \multirow{2}{*}{$\begin{array}{l}\text { Linear } \\
\text { regression }\end{array}$} & Training & 0.516 & 0.328 & 0.020 & 0.116 & 0.236 & 0.082 & 0.227 \\
\hline & Testing & 0.591 & 0.379 & -0.022 & -0.032 & -0.172 & 0.123 & 0.158 \\
\hline \multirow{2}{*}{$\begin{array}{l}\text { Neural } \\
\text { network }\end{array}$} & Training & 0.524 & 0.368 & 0.040 & 0.137 & 0.208 & 0.160 & 0.300 \\
\hline & Testing & 0.528 & 0.486 & -0.161 & -0.007 & -0.274 & 0.140 & 0.167 \\
\hline \multirow{2}{*}{$\begin{array}{l}\text { Random } \\
\text { forest }\end{array}$} & Training & 0.872 & 0.847 & 0.641 & 0.791 & 0.831 & 0.712 & 0.870 \\
\hline & Testing & 0.848 & 0.813 & 0.792 & 0.461 & 0.493 & 0.162 & 0.900 \\
\hline \multicolumn{9}{|c|}{ Predictor set 3: $G / R, B / G$, Mahalanobis distance } \\
\hline \multirow{2}{*}{$\begin{array}{l}\text { Linear } \\
\text { regression }\end{array}$} & Training & 0.521 & 0.345 & 0.026 & 0.116 & 0.234 & 0.098 & 0.356 \\
\hline & Testing & 0.580 & 0.374 & -0.043 & -0.026 & -0.140 & 0.166 & 0.233 \\
\hline \multirow{2}{*}{$\begin{array}{l}\text { Neural } \\
\text { network }\end{array}$} & Training & 0.241 & 0.392 & 0.056 & 0.132 & 0.155 & 0.124 & 0.262 \\
\hline & Testing & 0.271 & 0.482 & -0.354 & -0.229 & -0.196 & 0.061 & 0.254 \\
\hline \multirow{2}{*}{$\begin{array}{l}\text { Random } \\
\text { forest }\end{array}$} & Training & 0.882 & 0.826 & 0.767 & 0.734 & 0.815 & 0.792 & 0.839 \\
\hline & Testing & 0.811 & 0.806 & 0.373 & 0.616 & 0.492 & 0.675 & 0.786 \\
\hline
\end{tabular}




\begin{tabular}{|l|l|l|l|l|l|l|l|l|}
\hline \multirow{2}{*}{$\begin{array}{l}\text { Linear } \\
\text { regression }\end{array}$} & Training & 0.516 & 0.329 & 0.048 & 0.115 & 0.234 & 0.103 & 0.305 \\
\cline { 2 - 9 } & Testing & 0.593 & 0.383 & -0.046 & -0.023 & -0.140 & 0.124 & 0.156 \\
\hline \multirow{2}{*}{$\begin{array}{l}\text { Neural } \\
\text { network }\end{array}$} & Training & 0.251 & 0.335 & 0.092 & 0.109 & 0.155 & 0.128 & 0.283 \\
\cline { 2 - 9 } & Testing & 0.225 & 0.495 & -0.266 & -0.307 & -0.196 & 0.173 & 0.299 \\
\hline \multirow{2}{*}{$\begin{array}{l}\text { Random } \\
\text { forest }\end{array}$} & Training & 0.860 & 0.826 & 0.745 & 0.778 & 0.815 & 0.795 & 0.857 \\
\cline { 2 - 9 } & Testing & 0.815 & 0.782 & 0.286 & 0.577 & 0.492 & 0.675 & 0.838 \\
\hline
\end{tabular}

Note: The lamps are sorted from left to right in descending order of their relative percentages (see results of unmixing analysis, reported in Table S1).

Since models with the predictor sets $2^{\text {nd- }} 4^{\text {th }}$ demonstrate similar performance, and proceeding from consideration of calculation simplicity, we run random forest models with $\mathrm{G} / \mathrm{R}, \mathrm{B} / \mathrm{G}$, and GG/RB ratios as predictors upon all pixels of the calibrated ISS image (see Fig.1(b)). Fig. 7 reports resulting maps for two the most frequent lamp types' (HPS and MH) prevalence in Haifa. As can be seen from the figure, relatively higher contribution of HPS lamps in the outdoor lighting in Haifa coincide with the spatial pattern of municipal roads (see Fig. $7(a)$ ), while the pattern for MH lamps is more local and site-specific (see Fig. $7(b)$ ). In some regions of interest, HPS and MH lamps contribute to the outdoor lighting reversely. For example, in the Haifa Bay area, the impact of HPS lamps is pronounced while MH lamps are absent (see Figs. $7(c)$ ); in contrast, in the areas hosting Khof Shemen industrial zone and Haifa airport, MH lamps are widely used while HPS lamps are absent (see Fig. $7(d))$. 


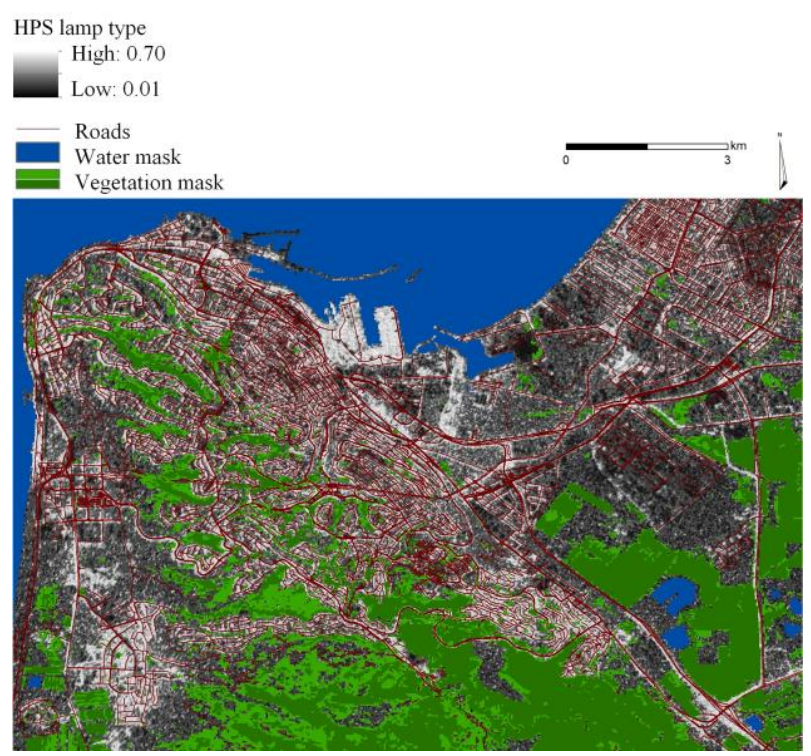

(a)

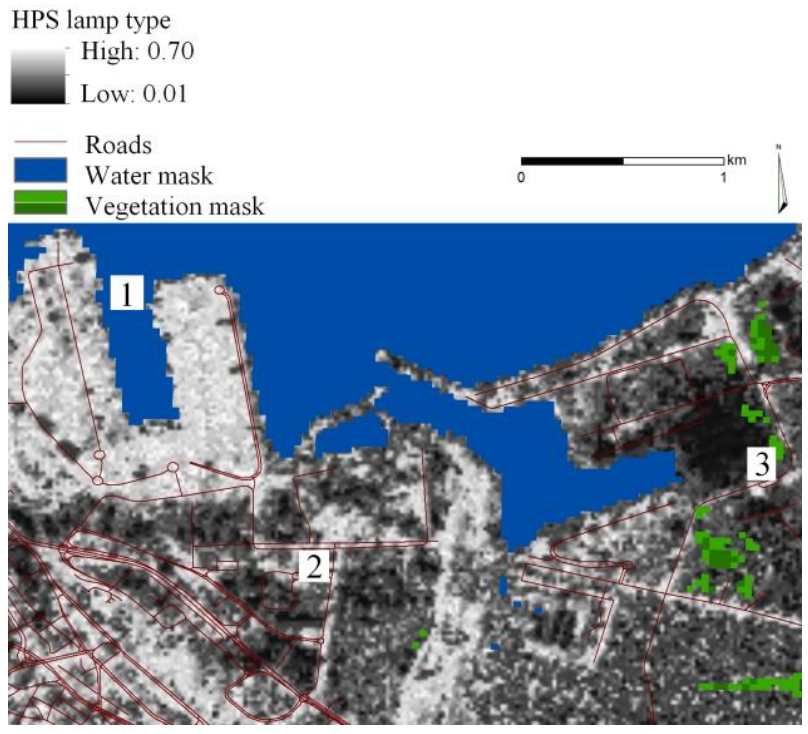

(c)

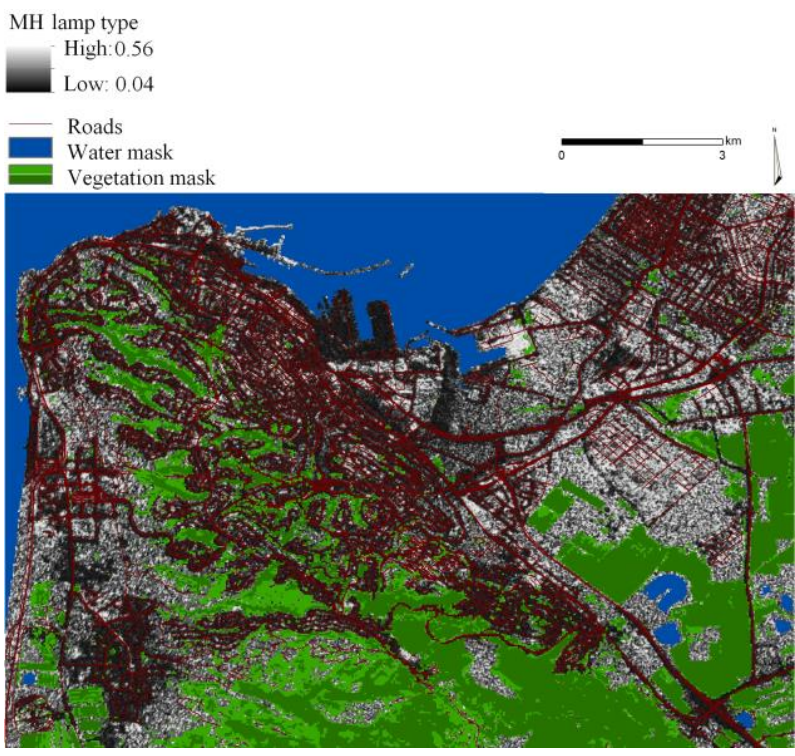

(b)

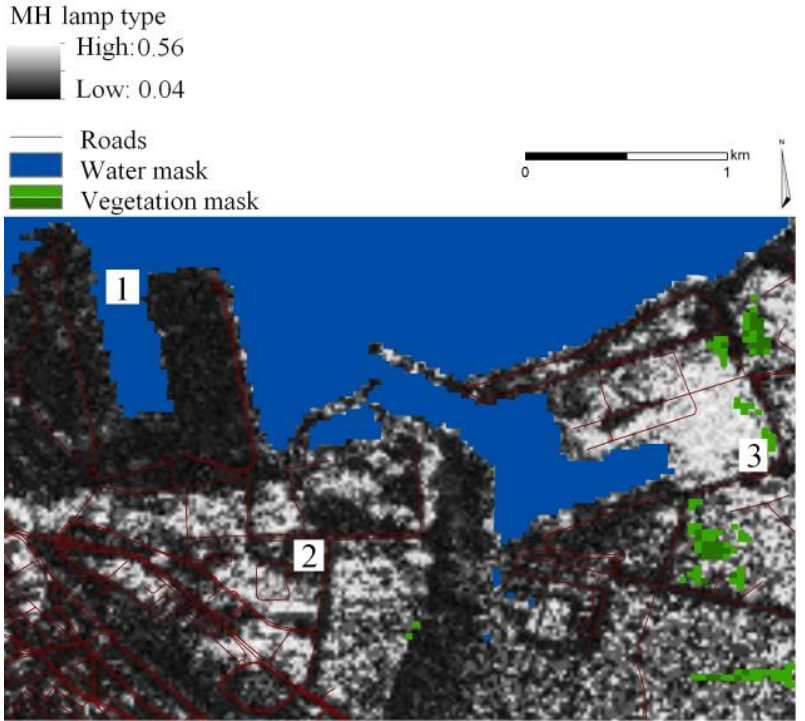

(d)

Figure 7: Model-anticipated relative contribution of High Pressure Sodium $((a) \&(c))$ and Metal Halide $((b) \&(d))$ lamps in the outdoor lighting in Haifa area $((a) \&(b))$ and selected ROIs $((c) \&(d))$ : "1" = Haifa Bay Area; "2" = Khof Shemen Industrial Zone; "3” = Haifa Airport.

Note: Water and vegetation masks (marked respectively blue and green) were produced from Landsat 8 OLI/TIRS C2 L2 dataset image (path 174 row 037) acquired on June 8, 2015 ("EarthExplorer," n.d.). For vegetation mask, normalized difference vegetation index (NDVI) was calculated as NDVI $=($ Band5 - Band6)/(Band5 + Band6) ("Landsat Normalized Difference Vegetation Index," n.d.), and levels in 0.22-0.25 and >0.25 diapasons were marked as light and dark green. For water mask, normalized difference moisture index (NDMI) was calculated as NDMI = (Band5 - Band4)/(Band5 + Band4) ("Normalized Difference Moisture Index," n.d.), and levels exceeding ... were marked blue. 


\section{Discussion}

In the present study, we tested for the possibility to identify on-ground lamp types from freely available satellite imagery of relatively coarse spatial and spectral resolution. To this end, we conducted a series of in situ NTL measurements in Haifa, Israel, and combined these data with a radiometrically calibrated NTL image of the city taken from the ISS. Since the ISS image is of 20-meter resolution, each pixel likely represents light emission from a mixture of lamps. By applying unmixing analysis to the detailed spectral signatures, we estimated the relative contributions of different lamp types in the in situ measurements. Then, we tried to train statistical models to predict these contributions based exclusively on the ISS image, which represents broad spectral RGB bands.

As our analysis indicates, contributions of two the most widespread lamp types in the region, HPS and $\mathrm{MH}$ lamps, could be successfully predicted (with adjusted $R^{2}$ reaching 0.882 for the training and 0.848 for the testing sets) by random forest models. Using them, we restored HPS and MH lamps' contribution into outdoor lighting in all Haifa area. The obtained HPS map demonstrated high concordance with the network of municipal roads, while $\mathrm{MH}$ map showed notable coincidence with industrial facilities and airport (see Fig. 7).

In the developed models, we used three explanatory variables. Two of them, $G / R$ and $B / G$ ratios, are similar to those previously used by Sánchez de Miguel (2019). An additional informative predictor described a 'proximity' of the analysed pixel of the ISS image to the lamp type in question. Interestingly, it turned out that lamps of the same type form clear-cut line segmentshaped loci in the $\mathrm{G} / \mathrm{R}, \mathrm{B} / \mathrm{G}$ coordinate plane (see Fig. 5). With this respect, we tried three alternative formalizations for the above-mentioned proximity: GG/RB ratio of the pixel, its Euclidean distance to the line, and, and its Mahalanobis distance to the locus. Without this 
additional explanatory variable, the models' performance was somewhat worse (with adjusted $R^{2}<0.861$ for the training and $R^{2}<0.828$ for the testing sets).

It should be mentioned that both Elvidge et al. (2010), Hale et al. (2013), and Zheng et al. (2018) reached remarkably high classification accuracy (with errors $4.7 \%, 7.5 \%$, and $16.1 \%$ respectively). However, their results cannot be directly compared with those presented here since we solved regression rather than classification problem, implying continuous rather that binary dependent variable. Yet, it seems reasonable to expect better performance of our models if they were based on an image of better spectral (like in (Elvidge et al., 2010)) and/or spatial (like in (Hale et al., 2013; Zheng et al., 2018)) resolution. Again, as mentioned above, we used the ISS image intentionally - given its free availability for many geographical sites. We think that our results argue for the principal possibility to assess the lamp type composition of outdoor lighting from the color satellite imagery.

Some limitations and perspectives of the study should be mentioned. First, proceeding from the available data, we did not succeed to obtain a reasonable spatial pattern for LEDs' contribution in the outdoor lighting in Haifa. A trivial reason may be insufficiency of the used data (small sample size, low prevalence of LEDs in the studied region in 2015). It also seems possible that the ISS imagery does not allow discriminating LEDs due to their high spectral variability and, therefore, overlapping with some other lamp types (which becomes even more pronounced after considering the reflectance of the ground), such as MH lamps, in the B/G, G/R space (Sánchez de Miguel et al., 2019). It should be mentioned that Elvidge et al. (2010) did succeed to discriminate LED lamps from other types since they used almost non-overlapping red, green, blue, and NIR bands. Nowadays, LEDs' popularity grows rapidly (Alamús et al., 2017; Elvidge et al., 2010; Sánchez de Miguel et al., 2019; Schubert and Kim, 2005) mainly due to their versatility and energy saving 
potential, and some precedents of total LED-based street lighting already exist (Kyba et al., 2020; Sánchez de Miguel et al., 2019). At the same time, LEDs’ primary emission peak, 450-460 nm (Elvidge et al., 2010), extremely distorts circadian rhythms and suppresses melatonin production in humans, contributing to sleep disorders (Czeisler, 2013), obesity (McFadden et al., 2014), hormone-dependent cancers (Haim and Portnov, 2013), and other diseases. Thus, further analysis is needed to explore the possibility to identify LED lamps from the ISS-provided imagery. It seems promising to exploit, in addition to ISS imagery, VIIRS-provided data, which covers also NIR diapason on night-time light.

Second, acquisition time of the used ISS-provided image and of the in situ NTL measurements do not coincide perfectly, which may cause some inaccuracy in the herein obtained estimates. However, weather conditions in Israel are rather similar in March (when the in situ measurements were conducted) and in November (when the ISS image was taken). Additionally, our sample did not include observations from residential areas, which brightness may vary during the night (Bará et al., 2019); instead, it included observations along major roads, entertainment areas, hospitals, and high-tech enterprises - that is, represented by streetlights of nearly-constant brightness during the night.

\section{Conclusions}

Numerous medical and environmental studies have shown that night-time light of different spectra differs in its impact on human and ecosystem health. With this respect, the development of smart and precise policies for diminishing the adverse effects of light pollution requires fine-tuned analysis of multispectral satellite imagery which would enable remote recognition of different onground light sources. In the present study, we introduce a new approach to discriminate between lamp types proceeding from the freely available night-time ISS imagery and test it over the Haifa 
region, Israel. At the first stage, we applied unmixing analysis to the detailed spectral signatures of in situ measurements - to characterize each measurement by a set of percentages estimating the relative contributions of different lamp types to the overall light emission. Afterward, we matched the in situ measurements with the corresponding pixels in the ISS image and used the RGB characteristics (that is, $\mathrm{G} / \mathrm{R}, \mathrm{B} / \mathrm{G}$ ratios, and the ratio between the two) of these pixels as explanatory variables in a set of machine learning techniques - to predict the earlier obtained percentages of different lamp types. For two lamp types, HPS and MH lamps, the predictions appeared fairly accurate. The restored maps of the relative contribution of these lamp types demonstrated high spatial concordance with specific on-ground activities, such as the network of municipal roads (for HPS lamps) and industrial facilities and airport (for MH lamps). These two lighting sources are the most widespread in the study area. The third popular lighting source, LED lamps, appeared hard to predict. A possible way to discriminate LED lamps may be combining ISS imagery with VIIRS data since the latter cover also NIR diapason. Such a fusion is a promising direction for future investigations.

\section{Funding:}

This work was supported by the Council for Higher Education of Israel and Cities at Night Project.

\section{References:}

Alamús, R., Bará, S., Corbera, J., Escofet, J., Palà, V., Pipia, L., Tardà, A., 2017. Ground-based hyperspectral analysis of the urban nightscape. ISPRS J. Photogramm. Remote Sens. 124, 16-26. https://doi.org/10.1016/J.ISPRSJPRS.2016.12.004

Bará, S., Rodríguez-Arós, Pérez, M., Tosar, B., Lima, R.C., Sánchez de Miguel, A., Zamorano, J., 2019. Estimating the relative contribution of streetlights, vehicles, and residential lighting to the urban night sky brightness. Light. Res. Technol. 51, 1092-1107. https://doi.org/10.1177/1477153518808337 
The paper as a non-peer reviewed EarthArXiv preprint

Brainard, G.C., Hanifin, J.R., Greeson, J.M., Byrne, B., Glickman, G., Gerner, E., Rollag, M.D., 2001. Action spectrum for melatonin regulation in humans: Evidence for a novel circadian photoreceptor. J. Neurosci. 21, 6405-6412. https://doi.org/10.1523/jneurosci.21-16-06405.2001

Bro, R., De Jong, S., 1997. A fast non-negativity-constrained least squares algorithm. J. Chemom. 11, 393-401. https://doi.org/10.1002/(SICI)1099-128X(199709/10)11:5<393::AID-CEM483>3.0.CO;2-L

Cho, S., Lee, M., Choi, H., Korean, H.K.-J. of the, 2011, undefined, 2011. Calculation and Regulation Proposal of Light Pollution from Road Lightings. koreascience.or.kr 21-26. https://doi.org/10.5207/JIEIE.2011.25.12.021

Cinzano, P., Falchi, F., Elvidge, C.D., 2001. The first World Atlas of the artificial night sky brightness. Mon. Not. R. Astron. Soc. 328, 689-707. https://doi.org/10.1046/j.1365-8711.2001.04882.x

Czeisler, C.A., 2013. Perspective: Casting light on sleep deficiency. Nature 497, S13. https://doi.org/10.1038/497S13a

EarthExplorer [WWW Document], n.d. URL https://earthexplorer.usgs.gov/ (accessed 6.22.21).

Elvidge, C.D., Keith, D.M., Tuttle, B.T., Baugh, K.E., 2010. Spectral identification of lighting type and character. Sensors 10, 3961-3988. https://doi.org/10.3390/s100403961

Falchi, F., Bará, S., 2020. A linear systems approach to protect the night sky: implications for current and future regulations. R. Soc. Open Sci. 7. https://doi.org/10.1098/RSOS.201501

Falchi, F., Cinzano, P., Duriscoe, D., Kyba, C.C.M., Elvidge, C.D., Baugh, K., Portnov, B.A., Rybnikova, N.A., Furgoni, R., 2016. The new world atlas of artificial night sky brightness. Sci. Adv. 2, e1600377. https://doi.org/10.1126/sciadv.1600377

Garcia-Saenz, A., Sánchez de Miguel, A., Espinosa, A., Valentin, A., Aragonés, N., Llorca, J., Amiano, P., Martín Sánchez, V., Guevara, M., Capelo, R., Tardón, A., Peiró-Perez, R., Jiménez-Moleón, J.J., Roca-Barceló, A., Pérez-Gómez, B., Dierssen-Sotos, T., Fernández-Villa, T., Moreno-Iribas, C., Moreno, V., García-Pérez, J., Castaño-Vinyals, G., Pollán, M., Aubé, M., Kogevinas, M., 2018. Evaluating the Association between Artificial Light-at-Night Exposure and Breast and Prostate Cancer Risk in Spain (MCC-Spain Study). Environ. Health Perspect. 126, 047011. https://doi.org/10.1289/EHP1837 
The paper as a non-peer reviewed EarthArXiv preprint

Gaston, K., Duffy, J., Gaston, S., Bennie, J., Oecologia, T.D.-, 2014, U., 2014. Human alteration of natural light cycles: causes and ecological consequences. Oecologia.

Gaston, K.J., Bennie, J., Davies, T.W., Hopkins, J., 2013. The ecological impacts of nighttime light pollution: A mechanistic appraisal. Biol. Rev. 88, 912-927. https://doi.org/10.1111/brv.12036

Guk, E., Levin, N., 2020. Analyzing spatial variability in night-time lights using a high spatial resolution color Jilin1 image - Jerusalem as a case study. ISPRS J. Photogramm. Remote Sens. 163, 121-136. https://doi.org/10.1016/j.isprsjprs.2020.02.016

Haim, A., Portnov, B.A., 2013. Light pollution as a new risk factor for human breast and prostate cancers, Light Pollution as a New Risk Factor for Human Breast and Prostate Cancers. Springer Netherlands. https://doi.org/10.1007/978-94-007-6220-6

Hale, J.D., Davies, G., Fairbrass, A.J., Matthews, T.J., Rogers, C.D.F., Sadler, J.P., 2013. Mapping Lightscapes: Spatial Patterning of Artificial Lighting in an Urban Landscape. PLoS One 8. https://doi.org/10.1371/journal.pone.0061460

Hatori, M., Gronfier, C., ... R.V.G.A. and, 2017, U., 2017. Global rise of potential health hazards caused by blue light-induced circadian disruption in modern aging societies. nature.com.

Hölker, F., Wolter, C., Perkin, E.K., Tockner, K., 2010. Light pollution as a biodiversity threat. Trends Ecol. Evol. https://doi.org/10.1016/j.tree.2010.09.007

Home - Savestars Consulting S.L. [WWW Document], n.d. URL http://www.savestarsconsulting.com/en/index/ (accessed 5.6.21).

Huang, X., Yang, J., Li, J., Wen, D., 2021. Urban functional zone mapping by integrating high spatial resolution nighttime light and daytime multi-view imagery. ISPRS J. Photogramm. Remote Sens. 175, 403-415. https://doi.org/10.1016/J.ISPRSJPRS.2021.03.019

Illuminance Spectrophotometer CL-500A [WWW Document], n.d. URL https://www.konicaminolta.com/instruments/download/catalog/light/pdf/cl500a_catalog_eng.pdf (accessed 5.6.21). 
The paper as a non-peer reviewed EarthArXiv preprint

Kloog, I., Haim, A., Stevens, R.G., Portnov, B.A., 2009. Global co-distribution of light at night (LAN) and cancers of prostate, colon, and lung in men. Chronobiol. Int. 26, 108-125.

Kyba, C.C.M., 2018. Is light pollution getting better or worse? Nat. Astron. https://doi.org/10.1038/s41550-018$0402-7$

Kyba, C.C.M., Kuester, T., De Miguel, A.S., Baugh, K., Jechow, A., Hölker, F., Bennie, J., Elvidge, C.D., Gaston, K.J., Guanter, L., 2017. Artificially lit surface of Earth at night increasing in radiance and extent. Sci. Adv. 3, e1701528. https://doi.org/10.1126/sciadv.1701528

Kyba, C.C.M., Ruby, A., Kuechly, H.U., Kinzey, B., Miller, N., Sanders, J., Barentine, J., Kleinodt, R., Espey, B., 2020. Direct measurement of the contribution of street lighting to satellite observations of nighttime light emissions from urban areas. Light. Res. Technol. https://doi.org/10.1177/1477153520958463

Landsat Normalized Difference Vegetation Index [WWW Document], n.d. URL https://www.usgs.gov/corescience-systems/nli/landsat/landsat-normalized-difference-vegetation-index?qtscience_support_page_related_con=0\#qt-science_support_page_related_con (accessed 6.22.21).

Levin, N., Duke, Y., 2012. High spatial resolution night-time light images for demographic and socio-economic studies. Remote Sens. Environ. 119, 1-10. https://doi.org/10.1016/j.rse.2011.12.005

Lockley, S., ... G.B.-T.J. of clinical, 2003, U., 2003. High sensitivity of the human circadian melatonin rhythm to resetting by short wavelength light. J. Clin. Endocrinol. Metab. 88, 4502-4505.

Longcore, T., Environment, C.R.-F. in E. and the, 2004, U., 2004. Ecological light pollution. Wiley Online Libr.

Lyytimäki, J., 2015. Towards eco-efficient and enjoyable lighting. Br. GSDR.

Mahalanobis, P., 1936. On the generalized distance in statistics.

McFadden, E., Jones, M.E., Schoemaker, M.J., Ashworth, A., Swerdlow, A.J., 2014. The relationship between obesity and exposure to light at night: cross-sectional analyses of over 100,000 women in the Breakthrough Generations Study. Am. J. Epidemiol. 180, 245-250.

MODTRAN® [WWW Document], n.d. URL http://modtran.spectral.com/ (accessed 6.13.21). 
The paper as a non-peer reviewed EarthArXiv preprint

Morgan-Taylor, M., 2015. Regulating light pollution in Europe: Legal challenges and ways forward.

Normalized Difference Moisture Index [WWW Document], n.d. URL https://www.usgs.gov/core-sciencesystems/nli/landsat/normalized-difference-moisture-index (accessed 6.22.21).

Owens, A.C.S., Cochard, P., Durrant, J., Farnworth, B., Perkin, E.K., Seymoure, B., 2020. Light pollution is a driver of insect declines. Biol. Conserv. 241, 108259. https://doi.org/10.1016/j.biocon.2019.108259

Papamichael, C., Skene, D.J., Revell, V.L., 2012. Human Nonvisual Responses to Simultaneous Presentation of Blue and Red Monochromatic Light: http://dx.doi.org/10.1177/0748730411431447 27, 70-78. https://doi.org/10.1177/0748730411431447

Riegel, K.W., 1973. Light pollution. Science (80-. ). 179, 1285-1291. https://doi.org/10.1126/science.179.4080.1285

Rybnikova, N.A., Portnov, B.A., 2017. Remote identification of research and educational activities using spectral properties of nighttime light. ISPRS J. Photogramm. Remote Sens. 128, 212-222. https://doi.org/10.1016/j.isprsjprs.2017.03.021

Sánchez de Miguel, A., 2021. Colour remote sensing of the impact of artificial light at night (II): Calibration of DSLR-based images from the International Space Station. Press.

Sánchez de Miguel, A., Kyba, C.C.M., Aubé, M., Zamorano, J., Cardiel, N., Tapia, C., Bennie, J., Gaston, K.J., 2019. Colour remote sensing of the impact of artificial light at night (I): The potential of the International Space Station and other DSLR-based platforms. Remote Sens. Environ. 224, 92-103. https://doi.org/10.1016/j.rse.2019.01.035

Schroer, S., Karlicek, F.H.-L.T., R., U., Sun, U., C.-C, U., 2016, U., 2016. Impact of Lighting on Flora and Fauna. researchgate.net. https://doi.org/10.1007/978-3-319-00295-8_42-1

Schubert, E.F., Kim, J.K., 2005. Solid-state light sources getting smart. Science (80-. ). https://doi.org/10.1126/science.1108712

Search Photos [WWW Document], n.d. URL https://eol.jsc.nasa.gov/SearchPhotos/ (accessed 4.7.20).

Shi, C., Wang, L., 2014. Incorporating spatial information in spectral unmixing: A review. Remote Sens. Environ. 
The paper as a non-peer reviewed EarthArXiv preprint

https://doi.org/10.1016/j.rse.2014.03.034

Tapia Ayuga, C., Sánchez de Miguel, A., Zamorano Calvo, J., 2017. LICA-UCM lamps spectral database. Ene 8, 29.

Wiltschko, W., Munro, U., Ford, H., Wiltschko, R., 1993. Red light disrupts magnetic orientation of migratory birds. Nature 364, 525-527. https://doi.org/10.1038/364525a0

Zhang, Q., Wang, P., Chen, H., Huang, Q., Jiang, H., Zhang, Z., Zhang, Y., Luo, X., Sun, S., 2017. A novel method for urban area extraction from VIIRS DNB and MODIS NDVI data: a case study of Chinese cities. Int. J. Remote Sens. 38, 6094-6109. https://doi.org/10.1080/01431161.2017.1339927

Zheng, Q., Weng, Q., Huang, L., Wang, K., Deng, J., Jiang, R., Ye, Z., Gan, M., 2018. A new source of multispectral high spatial resolution night-time light imagery—JL1-3B. Remote Sens. Environ. 215, 300-312. https://doi.org/10.1016/J.RSE.2018.06.016

Zheng, Q., Weng, Q., Wang, K., 2021. Characterizing urban land changes of 30 global megacities using nighttime light time series stacks. ISPRS J. Photogramm. Remote Sens. 173, 10-23. https://doi.org/10.1016/J.ISPRSJPRS.2021.01.002 


\section{SUPPLEMENTARY MATERIAL}

Table S1: Unmixing results: The share of each lamp type in the detailed spectral signature of in situ observation (see text for explanation)

\begin{tabular}{|c|c|c|c|c|c|c|c|c|c|}
\hline \multirow{2}{*}{$\begin{array}{l}\text { In situ obs. } \\
\text { number }\end{array}$} & \multicolumn{7}{|c|}{$\begin{array}{c}\text { Share of lamp type in in situ observation detailed } \\
\text { spectral signature (unmixing results) }\end{array}$} & \multicolumn{2}{|c|}{$\begin{array}{l}\text { Max correlation between detailed } \\
\text { signatures of in situ obs. and lamps }\end{array}$} \\
\hline & $\mathrm{CFL}$ & MH & HPS & LPS & $\begin{array}{c}\text { Incan } \\
\mathrm{d}\end{array}$ & MV & LED & Correlation & Lamp type \\
\hline 504 & 0.085 & 0.659 & 0.067 & 0.060 & 0.014 & 0.000 & 0.114 & 0.720 & LED \\
\hline 185 & 0.197 & 0.176 & 0.305 & 0.080 & 0.030 & 0.000 & 0.213 & 0.911 & LED \\
\hline 566 & 0.022 & 0.058 & 0.201 & 0.044 & 0.568 & 0.009 & 0.097 & 0.957 & Incand \\
\hline 467 & 0.000 & 0.024 & 0.772 & 0.054 & 0.000 & 0.000 & 0.150 & 0.945 & HPS \\
\hline 238 & 0.194 & 0.072 & 0.323 & 0.000 & 0.008 & 0.307 & 0.095 & 0.634 & MV \\
\hline 231 & 0.195 & 0.058 & 0.265 & 0.000 & 0.000 & 0.389 & 0.093 & 0.654 & MV \\
\hline 97 & 0.000 & 0.065 & 0.664 & 0.169 & 0.000 & 0.000 & 0.101 & 0.937 & HPS \\
\hline 465 & 0.000 & 0.024 & 0.760 & 0.103 & 0.000 & 0.000 & 0.113 & 0.930 & HPS \\
\hline 286 & 0.083 & 0.465 & 0.336 & 0.000 & 0.000 & 0.000 & 0.116 & 0.747 & LED \\
\hline 570 & 0.097 & 0.287 & 0.052 & 0.059 & 0.049 & 0.000 & 0.456 & 0.946 & LED \\
\hline 112 & 0.040 & 0.305 & 0.372 & 0.243 & 0.013 & 0.000 & 0.026 & 0.806 & HPS \\
\hline 565 & 0.000 & 0.019 & 0.151 & 0.027 & 0.638 & 0.002 & 0.164 & 0.979 & Incand \\
\hline 431 & 0.000 & 0.056 & 0.671 & 0.151 & 0.036 & 0.000 & 0.087 & 0.889 & HPS \\
\hline 466 & 0.000 & 0.024 & 0.755 & 0.100 & 0.000 & 0.000 & 0.121 & 0.932 & HPS \\
\hline 433 & 0.000 & 0.085 & 0.629 & 0.119 & 0.000 & 0.000 & 0.166 & 0.913 & LED \\
\hline 107 & 0.000 & 0.076 & 0.595 & 0.298 & 0.000 & 0.000 & 0.031 & 0.891 & HPS \\
\hline 451 & 0.074 & 0.543 & 0.272 & 0.046 & 0.000 & 0.000 & 0.066 & 0.777 & MH \\
\hline 1 & 0.247 & 0.098 & 0.161 & 0.000 & 0.000 & 0.386 & 0.108 & 0.670 & MV \\
\hline 250 & 0.237 & 0.042 & 0.141 & 0.000 & 0.002 & 0.480 & 0.098 & 0.663 & MV \\
\hline 432 & 0.000 & 0.068 & 0.608 & 0.075 & 0.062 & 0.000 & 0.187 & 0.936 & LED \\
\hline 430 & 0.016 & 0.007 & 0.729 & 0.000 & 0.052 & 0.000 & 0.195 & 0.938 & HPS \\
\hline 103 & 0.000 & 0.084 & 0.658 & 0.204 & 0.000 & 0.000 & 0.054 & 0.922 & HPS \\
\hline 68 & 0.008 & 0.327 & 0.412 & 0.162 & 0.000 & 0.000 & 0.091 & 0.782 & HPS \\
\hline 36 & 0.000 & 0.157 & 0.646 & 0.104 & 0.000 & 0.000 & 0.093 & 0.935 & HPS \\
\hline 453 & 0.077 & 0.555 & 0.279 & 0.025 & 0.000 & 0.000 & 0.065 & 0.776 & MH \\
\hline 168 & 0.025 & 0.358 & 0.478 & 0.045 & 0.000 & 0.000 & 0.094 & 0.849 & HPS \\
\hline 40 & 0.000 & 0.058 & 0.674 & 0.176 & 0.000 & 0.000 & 0.092 & 0.935 & HPS \\
\hline 64 & 0.021 & 0.345 & 0.411 & 0.148 & 0.000 & 0.000 & 0.074 & 0.741 & HPS \\
\hline 440 & 0.007 & 0.184 & 0.584 & 0.107 & 0.000 & 0.000 & 0.118 & 0.898 & HPS \\
\hline 452 & 0.078 & 0.551 & 0.269 & 0.041 & 0.000 & 0.000 & 0.062 & 0.775 & $\mathrm{MH}$ \\
\hline 264 & 0.020 & 0.030 & 0.029 & 0.004 & 0.873 & 0.000 & 0.044 & 0.997 & Incand \\
\hline 256 & 0.000 & 0.739 & 0.000 & 0.000 & 0.121 & 0.000 & 0.140 & 0.832 & $\mathrm{MH}$ \\
\hline 261 & 0.392 & 0.152 & 0.235 & 0.045 & 0.026 & 0.000 & 0.149 & 0.843 & LED \\
\hline 397 & 0.068 & 0.382 & 0.168 & 0.060 & 0.020 & 0.000 & 0.301 & 0.852 & LED \\
\hline 109 & 0.000 & 0.081 & 0.586 & 0.311 & 0.000 & 0.000 & 0.023 & 0.885 & HPS \\
\hline 445 & 0.036 & 0.511 & 0.294 & 0.116 & 0.008 & 0.000 & 0.035 & 0.803 & MH \\
\hline
\end{tabular}


The paper as a non-peer reviewed EarthArXiv preprint

\begin{tabular}{|c|c|c|c|c|c|c|c|c|c|}
\hline \multirow{2}{*}{$\begin{array}{l}\text { In situ obs. } \\
\text { number }\end{array}$} & \multicolumn{7}{|c|}{$\begin{array}{c}\text { Share of lamp type in in situ observation detailed } \\
\text { spectral signature (unmixing results) }\end{array}$} & \multicolumn{2}{|c|}{$\begin{array}{l}\text { Max correlation between detailed } \\
\text { signatures of in situ obs. and lamps }\end{array}$} \\
\hline & CFL & $\mathrm{MH}$ & HPS & LPS & $\begin{array}{c}\text { Incan } \\
\mathrm{d}\end{array}$ & MV & LED & Correlation & Lamp type \\
\hline 38 & 0.020 & 0.092 & 0.604 & 0.134 & 0.000 & 0.000 & 0.150 & 0.928 & LED \\
\hline 450 & 0.076 & 0.570 & 0.266 & 0.010 & 0.000 & 0.000 & 0.079 & 0.762 & MH \\
\hline 528 & 0.124 & 0.154 & 0.384 & 0.068 & 0.000 & 0.155 & 0.116 & 0.725 & LED \\
\hline 104 & 0.000 & 0.086 & 0.614 & 0.268 & 0.000 & 0.000 & 0.032 & 0.900 & HPS \\
\hline 559 & 0.516 & 0.036 & 0.161 & 0.000 & 0.000 & 0.203 & 0.085 & 0.789 & CFL \\
\hline 590 & 0.123 & 0.604 & 0.000 & 0.069 & 0.109 & 0.000 & 0.095 & 0.838 & MH \\
\hline 29 & 0.114 & 0.090 & 0.525 & 0.094 & 0.002 & 0.000 & 0.174 & 0.930 & LED \\
\hline 35 & 0.000 & 0.038 & 0.758 & 0.087 & 0.000 & 0.000 & 0.116 & 0.935 & HPS \\
\hline 608 & 0.088 & 0.552 & 0.000 & 0.020 & 0.092 & 0.000 & 0.248 & 0.881 & LED \\
\hline 187 & 0.004 & 0.123 & 0.574 & 0.151 & 0.008 & 0.000 & 0.140 & 0.927 & HPS \\
\hline 31 & 0.055 & 0.060 & 0.640 & 0.152 & 0.000 & 0.000 & 0.093 & 0.926 & HPS \\
\hline 129 & 0.000 & 0.052 & 0.693 & 0.181 & 0.000 & 0.000 & 0.074 & 0.931 & HPS \\
\hline 508 & 0.409 & 0.409 & 0.044 & 0.000 & 0.000 & 0.025 & 0.112 & 0.714 & CFL \\
\hline 260 & 0.034 & 0.675 & 0.149 & 0.086 & 0.000 & 0.000 & 0.057 & 0.752 & $\mathrm{MH}$ \\
\hline 558 & 0.450 & 0.014 & 0.167 & 0.000 & 0.000 & 0.277 & 0.092 & 0.759 & $\mathrm{CFL}$ \\
\hline 529 & 0.107 & 0.195 & 0.425 & 0.090 & 0.000 & 0.072 & 0.110 & 0.735 & LED \\
\hline 556 & 0.532 & 0.038 & 0.153 & 0.000 & 0.000 & 0.198 & 0.079 & 0.797 & CFL \\
\hline 564 & 0.000 & 0.045 & 0.239 & 0.060 & 0.455 & 0.000 & 0.202 & 0.934 & Incand \\
\hline 518 & 0.013 & 0.027 & 0.103 & 0.045 & 0.049 & 0.000 & 0.762 & 0.983 & LED \\
\hline 495 & 0.641 & 0.221 & 0.000 & 0.021 & 0.000 & 0.000 & 0.117 & 0.768 & CFL \\
\hline 69 & 0.086 & 0.047 & 0.647 & 0.080 & 0.000 & 0.000 & 0.139 & 0.937 & LED \\
\hline 429 & 0.000 & 0.045 & 0.688 & 0.000 & 0.070 & 0.000 & 0.197 & 0.930 & HPS \\
\hline 101 & 0.000 & 0.071 & 0.643 & 0.179 & 0.000 & 0.000 & 0.106 & 0.934 & HPS \\
\hline 291 & 0.093 & 0.263 & 0.296 & 0.000 & 0.005 & 0.155 & 0.189 & 0.725 & LED \\
\hline 102 & 0.000 & 0.080 & 0.610 & 0.276 & 0.000 & 0.000 & 0.035 & 0.899 & HPS \\
\hline 139 & 0.000 & 0.195 & 0.516 & 0.218 & 0.000 & 0.000 & 0.071 & 0.885 & HPS \\
\hline 138 & 0.000 & 0.139 & 0.554 & 0.245 & 0.000 & 0.000 & 0.061 & 0.890 & HPS \\
\hline 509 & 0.113 & 0.602 & 0.126 & 0.000 & 0.000 & 0.043 & 0.115 & 0.716 & $\mathrm{MH}$ \\
\hline 100 & 0.000 & 0.086 & 0.547 & 0.367 & 0.000 & 0.000 & 0.000 & 0.841 & HPS \\
\hline 607 & 0.053 & 0.554 & 0.000 & 0.000 & 0.111 & 0.000 & 0.282 & 0.887 & LED \\
\hline 526 & 0.723 & 0.204 & 0.000 & 0.019 & 0.000 & 0.000 & 0.054 & 0.828 & CFL \\
\hline 449 & 0.063 & 0.524 & 0.266 & 0.112 & 0.000 & 0.000 & 0.035 & 0.824 & $\mathrm{MH}$ \\
\hline 517 & 0.038 & 0.184 & 0.492 & 0.219 & 0.000 & 0.000 & 0.067 & 0.840 & HPS \\
\hline 520 & 0.002 & 0.000 & 0.004 & 0.000 & 0.057 & 0.018 & 0.919 & 0.984 & LED \\
\hline 391 & 0.000 & 0.081 & 0.588 & 0.291 & 0.000 & 0.000 & 0.040 & 0.892 & HPS \\
\hline 46 & 0.219 & 0.093 & 0.098 & 0.000 & 0.000 & 0.000 & 0.590 & 0.954 & LED \\
\hline 523 & 0.016 & 0.133 & 0.439 & 0.373 & 0.000 & 0.000 & 0.040 & 0.766 & HPS \\
\hline 519 & 0.028 & 0.002 & 0.009 & 0.000 & 0.060 & 0.021 & 0.880 & 0.984 & LED \\
\hline 84 & 0.077 & 0.091 & 0.665 & 0.000 & 0.023 & 0.000 & 0.144 & 0.949 & HPS \\
\hline 193 & 0.101 & 0.102 & 0.483 & 0.163 & 0.000 & 0.000 & 0.151 & 0.906 & LED \\
\hline
\end{tabular}


The paper as a non-peer reviewed EarthArXiv preprint

\begin{tabular}{|c|c|c|c|c|c|c|c|c|c|}
\hline \multirow{2}{*}{$\begin{array}{l}\text { In situ obs. } \\
\text { number }\end{array}$} & \multicolumn{7}{|c|}{$\begin{array}{c}\text { Share of lamp type in in situ observation detailed } \\
\text { spectral signature (unmixing results) }\end{array}$} & \multicolumn{2}{|c|}{$\begin{array}{l}\text { Max correlation between detailed } \\
\text { signatures of in situ obs. and lamps }\end{array}$} \\
\hline & CFL & MH & HPS & LPS & $\begin{array}{c}\text { Incan } \\
\mathrm{d}\end{array}$ & MV & LED & Correlation & Lamp type \\
\hline 589 & 0.032 & 0.645 & 0.000 & 0.000 & 0.179 & 0.000 & 0.144 & 0.810 & $\mathrm{MH}$ \\
\hline 524 & 0.032 & 0.127 & 0.365 & 0.252 & 0.000 & 0.000 & 0.225 & 0.858 & LED \\
\hline 591 & 0.474 & 0.419 & 0.000 & 0.018 & 0.025 & 0.000 & 0.064 & 0.747 & CFL \\
\hline 563 & 0.000 & 0.039 & 0.154 & 0.073 & 0.630 & 0.000 & 0.103 & 0.971 & Incand \\
\hline 474 & 0.062 & 0.465 & 0.270 & 0.138 & 0.000 & 0.000 & 0.065 & 0.756 & MH \\
\hline 16 & 0.028 & 0.013 & 0.189 & 0.021 & 0.028 & 0.019 & 0.701 & 0.977 & LED \\
\hline 41 & 0.000 & 0.012 & 0.777 & 0.085 & 0.000 & 0.000 & 0.126 & 0.942 & HPS \\
\hline 343 & 0.776 & 0.193 & 0.000 & 0.011 & 0.000 & 0.000 & 0.020 & 0.837 & CFL \\
\hline 32 & 0.000 & 0.102 & 0.532 & 0.366 & 0.000 & 0.000 & 0.000 & 0.832 & HPS \\
\hline 273 & 0.015 & 0.334 & 0.470 & 0.055 & 0.000 & 0.000 & 0.126 & 0.880 & LED \\
\hline 208 & 0.005 & 0.108 & 0.344 & 0.150 & 0.032 & 0.000 & 0.361 & 0.965 & LED \\
\hline 98 & 0.086 & 0.112 & 0.505 & 0.248 & 0.000 & 0.000 & 0.049 & 0.881 & HPS \\
\hline 228 & 0.031 & 0.187 & 0.525 & 0.147 & 0.000 & 0.000 & 0.110 & 0.911 & HPS \\
\hline 245 & 0.246 & 0.039 & 0.149 & 0.000 & 0.009 & 0.462 & 0.095 & 0.671 & MV \\
\hline 446 & 0.023 & 0.537 & 0.293 & 0.126 & 0.000 & 0.000 & 0.021 & 0.820 & $\mathrm{MH}$ \\
\hline 173 & 0.080 & 0.276 & 0.049 & 0.000 & 0.000 & 0.324 & 0.272 & 0.634 & $\mathrm{MH}$ \\
\hline 605 & 0.082 & 0.548 & 0.000 & 0.017 & 0.091 & 0.000 & 0.262 & 0.893 & LED \\
\hline 99 & 0.055 & 0.115 & 0.480 & 0.348 & 0.000 & 0.000 & 0.002 & 0.811 & HPS \\
\hline 601 & 0.768 & 0.169 & 0.000 & 0.000 & 0.000 & 0.000 & 0.063 & 0.859 & CFL \\
\hline 18 & 0.165 & 0.103 & 0.375 & 0.000 & 0.004 & 0.223 & 0.129 & 0.669 & LED \\
\hline 555 & 0.609 & 0.069 & 0.123 & 0.000 & 0.000 & 0.126 & 0.073 & 0.818 & CFL \\
\hline 530 & 0.473 & 0.079 & 0.080 & 0.030 & 0.000 & 0.062 & 0.275 & 0.772 & LED \\
\hline 263 & 0.033 & 0.039 & 0.130 & 0.055 & 0.657 & 0.000 & 0.085 & 0.977 & Incand \\
\hline 327 & 0.000 & 0.776 & 0.000 & 0.074 & 0.000 & 0.000 & 0.150 & 0.812 & MH \\
\hline 600 & \begin{tabular}{|l|}
0.767 \\
\end{tabular} & 0.165 & 0.000 & 0.000 & 0.000 & 0.000 & 0.068 & 0.856 & $\mathrm{CFL}$ \\
\hline 557 & 0.305 & 0.015 & 0.191 & 0.000 & 0.000 & 0.403 & 0.087 & 0.678 & MV \\
\hline 206 & 0.015 & 0.087 & 0.250 & 0.111 & 0.004 & 0.000 & 0.533 & 0.971 & LED \\
\hline 562 & 0.000 & 0.058 & 0.201 & 0.106 & 0.527 & 0.000 & 0.108 & 0.936 & Incand \\
\hline 265 & 0.024 & 0.015 & 0.038 & 0.013 & 0.895 & 0.002 & 0.012 & 0.999 & Incand \\
\hline 372 & 0.093 & 0.076 & 0.160 & 0.039 & 0.525 & 0.000 & 0.106 & 0.957 & Incand \\
\hline 604 & 0.032 & 0.525 & 0.000 & 0.000 & 0.115 & 0.000 & 0.328 & 0.916 & LED \\
\hline 6 & 0.099 & 0.612 & 0.200 & 0.027 & 0.004 & 0.000 & 0.059 & 0.776 & MH \\
\hline 606 & 0.047 & 0.558 & 0.000 & 0.000 & 0.114 & 0.000 & 0.282 & 0.885 & LED \\
\hline 45 & 0.407 & 0.139 & 0.295 & 0.044 & 0.000 & 0.000 & 0.115 & 0.827 & LED \\
\hline 266 & 0.052 & 0.031 & 0.032 & 0.010 & 0.843 & 0.000 & 0.032 & 0.998 & Incand \\
\hline 39 & 0.000 & 0.052 & 0.673 & 0.179 & 0.000 & 0.000 & 0.096 & 0.935 & HPS \\
\hline 15 & 0.019 & 0.014 & 0.089 & 0.013 & 0.037 & 0.022 & 0.805 & 0.976 & LED \\
\hline 51 & 0.085 & 0.184 & 0.423 & 0.007 & 0.000 & 0.102 & 0.199 & 0.775 & LED \\
\hline 583 & 0.094 & 0.573 & 0.217 & 0.000 & 0.000 & 0.000 & 0.115 & 0.729 & MH \\
\hline 584 & 0.098 & 0.617 & 0.206 & 0.000 & 0.000 & 0.000 & 0.078 & 0.776 & $\mathrm{MH}$ \\
\hline
\end{tabular}


The paper as a non-peer reviewed EarthArXiv preprint

\begin{tabular}{|c|c|c|c|c|c|c|c|c|c|}
\hline \multirow{2}{*}{$\begin{array}{l}\text { In situ obs. } \\
\text { number }\end{array}$} & \multicolumn{7}{|c|}{$\begin{array}{c}\text { Share of lamp type in in situ observation detailed } \\
\text { spectral signature (unmixing results) }\end{array}$} & \multicolumn{2}{|c|}{$\begin{array}{l}\text { Max correlation between detailed } \\
\text { signatures of } i n \text { situ obs. and lamps }\end{array}$} \\
\hline & CFL & MH & HPS & LPS & $\begin{array}{c}\text { Incan } \\
\mathrm{d}\end{array}$ & MV & LED & Correlation & Lamp type \\
\hline 42 & 0.002 & 0.197 & 0.620 & 0.060 & 0.000 & 0.000 & 0.121 & 0.893 & HPS \\
\hline 292 & 0.052 & 0.193 & 0.317 & 0.000 & 0.000 & 0.283 & 0.155 & 0.604 & MV \\
\hline 461 & 0.037 & 0.596 & 0.105 & 0.162 & 0.000 & 0.000 & 0.100 & 0.826 & MH \\
\hline 454 & 0.072 & 0.540 & 0.282 & 0.047 & 0.000 & 0.000 & 0.060 & 0.772 & $\mathrm{MH}$ \\
\hline 439 & 0.011 & 0.081 & 0.619 & 0.146 & 0.001 & 0.000 & 0.141 & 0.917 & HPS \\
\hline 471 & 0.057 & 0.469 & 0.271 & 0.141 & 0.000 & 0.000 & 0.062 & 0.772 & $\mathrm{MH}$ \\
\hline 63 & 0.019 & 0.404 & 0.417 & 0.120 & 0.000 & 0.000 & 0.041 & 0.810 & HPS \\
\hline 207 & 0.019 & 0.091 & 0.238 & 0.104 & 0.034 & 0.000 & 0.514 & 0.975 & LED \\
\hline 468 & 0.000 & 0.031 & 0.743 & 0.091 & 0.000 & 0.000 & 0.136 & 0.933 & HPS \\
\hline 585 & 0.151 & 0.436 & 0.187 & 0.000 & 0.000 & 0.078 & 0.148 & 0.652 & CFL \\
\hline 599 & 0.757 & 0.165 & 0.000 & 0.000 & 0.000 & 0.000 & 0.078 & 0.853 & CFL \\
\hline 197 & 0.114 & 0.138 & 0.415 & 0.210 & 0.000 & 0.000 & 0.123 & 0.887 & LED \\
\hline 571 & 0.032 & 0.450 & 0.116 & 0.118 & 0.085 & 0.000 & 0.198 & 0.891 & LED \\
\hline 434 & 0.000 & 0.080 & 0.687 & 0.131 & 0.000 & 0.000 & 0.101 & 0.928 & HPS \\
\hline 448 & 0.063 & 0.501 & 0.275 & 0.128 & 0.000 & 0.000 & 0.034 & 0.807 & MH \\
\hline 90 & 0.163 & 0.154 & 0.441 & 0.044 & 0.000 & 0.000 & 0.198 & 0.904 & LED \\
\hline 399 & 0.060 & 0.308 & 0.158 & 0.060 & 0.116 & 0.006 & 0.292 & 0.899 & LED \\
\hline 66 & 0.297 & 0.190 & 0.248 & 0.077 & 0.000 & 0.000 & 0.188 & 0.810 & LED \\
\hline 375 & 0.043 & 0.249 & 0.466 & 0.100 & 0.000 & 0.000 & 0.142 & 0.926 & LED \\
\hline 105 & 0.000 & 0.071 & 0.673 & 0.141 & 0.000 & 0.000 & 0.115 & 0.933 & HPS \\
\hline 309 & 0.003 & 0.243 & 0.583 & 0.049 & 0.000 & 0.000 & 0.122 & 0.913 & HPS \\
\hline 349 & 0.392 & 0.181 & 0.110 & 0.000 & 0.001 & 0.000 & 0.315 & 0.815 & LED \\
\hline 198 & 0.010 & 0.119 & 0.535 & 0.310 & 0.000 & 0.000 & 0.026 & 0.867 & HPS \\
\hline 475 & 0.055 & 0.488 & 0.255 & 0.142 & 0.000 & 0.000 & 0.060 & 0.780 & MH \\
\hline 267 & 0.027 & 0.027 & 0.029 & 0.010 & 0.872 & 0.000 & 0.035 & 0.998 & Incand \\
\hline 7 & 0.195 & 0.493 & 0.088 & 0.000 & 0.029 & 0.068 & 0.126 & 0.677 & LED \\
\hline 227 & 0.006 & 0.128 & 0.606 & 0.159 & 0.000 & 0.000 & 0.101 & 0.919 & HPS \\
\hline 199 & 0.003 & 0.111 & 0.549 & 0.312 & 0.000 & 0.000 & 0.025 & 0.871 & HPS \\
\hline 262 & 0.679 & 0.175 & 0.021 & 0.029 & 0.000 & 0.000 & 0.096 & 0.791 & CFL \\
\hline 244 & 0.239 & 0.042 & 0.147 & 0.000 & 0.048 & 0.432 & 0.093 & 0.672 & MV \\
\hline 189 & 0.099 & 0.041 & 0.627 & 0.042 & 0.000 & 0.000 & 0.191 & 0.922 & LED \\
\hline 5 & 0.041 & 0.569 & 0.274 & 0.084 & 0.000 & 0.000 & 0.032 & 0.817 & MH \\
\hline 52 & 0.125 & 0.229 & 0.276 & 0.055 & 0.000 & 0.099 & 0.217 & 0.832 & LED \\
\hline 376 & 0.060 & 0.251 & 0.449 & 0.097 & 0.000 & 0.000 & 0.142 & 0.930 & LED \\
\hline 545 & 0.024 & 0.139 & 0.523 & 0.297 & 0.000 & 0.000 & 0.018 & 0.829 & HPS \\
\hline 527 & 0.170 & 0.167 & 0.400 & 0.132 & 0.000 & 0.000 & 0.131 & 0.839 & LED \\
\hline 405 & 0.063 & 0.541 & 0.162 & 0.131 & 0.000 & 0.000 & 0.102 & 0.774 & MH \\
\hline 351 & 0.127 & 0.065 & 0.656 & 0.004 & 0.000 & 0.000 & 0.147 & 0.941 & HPS \\
\hline 44 & 0.014 & 0.109 & 0.643 & 0.006 & 0.000 & 0.049 & 0.178 & 0.886 & HPS \\
\hline 126 & 0.000 & 0.047 & 0.722 & 0.103 & 0.000 & 0.000 & 0.128 & 0.940 & HPS \\
\hline
\end{tabular}


The paper as a non-peer reviewed EarthArXiv preprint

\begin{tabular}{|c|c|c|c|c|c|c|c|c|c|}
\hline \multirow{2}{*}{$\begin{array}{l}\text { In situ obs. } \\
\text { number }\end{array}$} & \multicolumn{7}{|c|}{$\begin{array}{c}\text { Share of lamp type in in situ observation detailed } \\
\text { spectral signature (unmixing results) }\end{array}$} & \multicolumn{2}{|c|}{$\begin{array}{l}\text { Max correlation between detailed } \\
\text { signatures of in situ obs. and lamps }\end{array}$} \\
\hline & CFL & MH & HPS & LPS & $\begin{array}{c}\text { Incan } \\
\mathrm{d}\end{array}$ & MV & LED & Correlation & Lamp type \\
\hline 209 & 0.153 & 0.115 & 0.436 & 0.195 & 0.000 & 0.000 & 0.100 & 0.884 & LED \\
\hline 398 & 0.061 & 0.321 & 0.159 & 0.057 & 0.079 & 0.000 & 0.323 & 0.890 & LED \\
\hline 350 & 0.581 & 0.189 & 0.138 & 0.000 & 0.000 & 0.000 & 0.092 & 0.770 & CFL \\
\hline 462 & 0.041 & 0.610 & 0.107 & 0.143 & 0.000 & 0.000 & 0.099 & 0.828 & MH \\
\hline 241 & 0.230 & 0.039 & 0.151 & 0.000 & 0.000 & 0.484 & 0.096 & 0.671 & MV \\
\hline 521 & 0.023 & 0.007 & 0.028 & 0.004 & 0.054 & 0.032 & 0.851 & 0.985 & LED \\
\hline 404 & 0.054 & 0.572 & 0.128 & 0.146 & 0.000 & 0.000 & 0.100 & 0.816 & MH \\
\hline 569 & 0.238 & 0.063 & 0.000 & 0.000 & 0.000 & 0.000 & 0.699 & 0.950 & LED \\
\hline 352 & 0.052 & 0.058 & 0.148 & 0.000 & 0.005 & 0.000 & 0.737 & 0.976 & LED \\
\hline 2 & 0.216 & 0.296 & 0.061 & 0.000 & 0.000 & 0.242 & 0.185 & 0.648 & CFL \\
\hline 284 & 0.083 & 0.531 & 0.262 & 0.000 & 0.000 & 0.000 & 0.124 & 0.719 & MH \\
\hline 447 & 0.035 & 0.515 & 0.283 & 0.131 & 0.011 & 0.000 & 0.025 & 0.802 & $\mathrm{MH}$ \\
\hline 498 & 0.586 & 0.257 & 0.000 & 0.000 & 0.000 & 0.000 & 0.157 & 0.760 & $\mathrm{CFL}$ \\
\hline 108 & 0.000 & 0.058 & 0.642 & 0.141 & 0.000 & 0.000 & 0.159 & 0.928 & LED \\
\hline 196 & 0.064 & 0.098 & 0.577 & 0.132 & 0.000 & 0.000 & 0.129 & 0.925 & HPS \\
\hline 540 & 0.183 & 0.027 & 0.138 & 0.000 & 0.021 & 0.399 & 0.232 & 0.697 & LED \\
\hline 95 & 0.068 & 0.077 & 0.679 & 0.006 & 0.000 & 0.000 & 0.170 & 0.940 & HPS \\
\hline 85 & 0.016 & 0.135 & 0.611 & 0.054 & 0.010 & 0.000 & 0.175 & 0.938 & LED \\
\hline 141 & 0.000 & 0.288 & 0.462 & 0.126 & 0.000 & 0.000 & 0.124 & 0.877 & HPS \\
\hline 113 & 0.041 & 0.482 & 0.234 & 0.189 & 0.025 & 0.000 & 0.028 & 0.838 & MH \\
\hline 307 & 0.020 & 0.396 & 0.381 & 0.091 & 0.037 & 0.000 & 0.075 & 0.861 & LED \\
\hline 37 & 0.186 & 0.106 & 0.458 & 0.146 & 0.000 & 0.000 & 0.104 & 0.733 & LED \\
\hline 477 & 0.133 & 0.025 & 0.193 & 0.000 & 0.000 & 0.555 & 0.095 & 0.689 & MV \\
\hline 476 & 0.133 & 0.026 & 0.200 & 0.000 & 0.000 & 0.549 & 0.091 & 0.686 & MV \\
\hline 13 & 0.147 & 0.444 & 0.152 & 0.174 & 0.047 & 0.000 & 0.037 & 0.886 & MH \\
\hline 143 & 0.036 & 0.091 & 0.600 & 0.233 & 0.000 & 0.000 & 0.040 & 0.878 & HPS \\
\hline 542 & 0.181 & 0.027 & 0.139 & 0.000 & 0.033 & 0.391 & 0.230 & 0.701 & LED \\
\hline 437 & 0.000 & 0.105 & 0.601 & 0.218 & 0.000 & 0.000 & 0.077 & 0.879 & HPS \\
\hline 28 & 0.002 & 0.079 & 0.641 & 0.165 & 0.000 & 0.000 & 0.113 & 0.928 & HPS \\
\hline 578 & 0.117 & 0.549 & 0.049 & 0.010 & 0.072 & 0.000 & 0.203 & 0.850 & LED \\
\hline 580 & 0.092 & 0.583 & 0.162 & 0.000 & 0.022 & 0.000 & 0.143 & 0.806 & LED \\
\hline 582 & 0.111 & 0.549 & 0.178 & 0.000 & 0.000 & 0.018 & 0.145 & 0.684 & MH \\
\hline 541 & 0.174 & 0.029 & 0.127 & 0.000 & 0.035 & 0.371 & 0.264 & 0.755 & LED \\
\hline 200 & 0.000 & 0.114 & 0.607 & 0.169 & 0.000 & 0.000 & 0.109 & 0.922 & HPS \\
\hline 412 & 0.000 & 0.537 & 0.155 & 0.097 & 0.059 & 0.000 & 0.152 & 0.728 & LED \\
\hline 268 & 0.006 & 0.016 & 0.261 & 0.000 & 0.008 & 0.000 & 0.710 & 0.990 & LED \\
\hline 435 & 0.000 & 0.081 & 0.606 & 0.208 & 0.026 & 0.000 & 0.080 & 0.873 & HPS \\
\hline 218 & 0.051 & 0.354 & 0.333 & 0.121 & 0.015 & 0.000 & 0.126 & 0.893 & LED \\
\hline 561 & 0.000 & 0.103 & 0.373 & 0.200 & 0.230 & 0.000 & 0.095 & 0.826 & LED \\
\hline 534 & 0.100 & 0.109 & 0.457 & 0.217 & 0.000 & 0.063 & 0.055 & 0.795 & HPS \\
\hline
\end{tabular}


The paper as a non-peer reviewed EarthArXiv preprint

\begin{tabular}{|l|c|c|c|c|c|c|c|c|c|}
\hline \multirow{2}{*}{$\begin{array}{l}\text { In situ obs. } \\
\text { number }\end{array}$} & \multicolumn{4}{|c|}{ Share of lamp type in in situ observation detailed } & \multicolumn{3}{c|}{$\begin{array}{c}\text { Max correlation between detailed } \\
\text { signatures of } \text { in situ obs. and lamps }\end{array}$} \\
\cline { 2 - 10 } & CFL & MH & HPS & LPS & $\begin{array}{c}\text { Incan } \\
\text { d }\end{array}$ & MV & LED & Correlation & Lamp type \\
\hline Avg. & $\mathbf{0 . 1 1 1}$ & $\mathbf{0 . 2 2 0}$ & $\mathbf{0 . 3 2 8}$ & $\mathbf{0 . 0 8 8}$ & $\mathbf{0 . 0 5 2}$ & $\mathbf{0 . 0 4 4}$ & $\mathbf{0 . 1 5 6}$ & & \\
\hline
\end{tabular}

